\title{
Mortality Compression and Variability in Age at Death in India
}

\author{
Suryakant Yadav, Arokiasamy Perianayagam
}

\begin{abstract}
The global rise of life expectancy at birth has attracted worldwide interest, especially in understanding the pace of mortality transition in developing countries. In this study, we assess the progress of mortality transition in India during four decades between 1970 and 2013. We estimate measures of mortality compression and variability in age at death to assess the trends and patterns in mortality compression for India as a whole and its twelve biggest states. The results reveal an unequivocal convergence pattern in mortality compression across the states underpinned by the reduction in premature mortality and emerging homogeneity in mortality. Results by gender show that women are more homogenous in their mortality across the country because of an explicit reduction in the Gini coefficients at age 10 by the age group of 15-29 years. Mortality compression has changed in recent decades because of the increased survival of women in their reproductive ages, which marked a distinct phase of mortality transition in India. The pace of mortality transition, however, varies; adult mortality decline was greater than senescent mortality decline. These results show that India has passed the middle stage of mortality transition and has entered an early phase of low mortality.
\end{abstract}

Keywords: Mortality compression • Variability in age at death · Gini coefficient • Adult mortality $\cdot$ Premature mortality $\cdot$ Mortality transition

\section{Introduction}

\subsection{The stages of mortality transition}

The global rise of life expectancy at birth $\left(e_{0}\right)$ is attributed to improvements in mortality at all ages, which generally contribute to rising human longevity (Dowd et al. 2010; Vaupel 1986; Vaupel et al. 1998; Vaupe/ 2010). The mortality decline among infants and children initially affects the level of $e_{0}$ (Clark 2011; Moser et al. 2005; Wang et al. 2016). Adult mortality, the probability of dying between age 15 and 60, 
together with infant and child mortality decline are reshaping the age pattern of mortality (Cheung/Robine 2007; Heligman/Pollard 1980; Rau et al. 2008; Tuljapurkar et al. 2000). The transformations in the age pattern of mortality in conjunction with mortality decline results in mortality compression, a process in which deaths are concentrated in a narrow age interval of age at death (Cheung et al. 2005; Kannisto 2000, 2001; Myers/Manton 1984; Thatcher et al. 2010). The phenomenon of mortality compression and associated changes in other related phenomena such as variability in age at death or degree of inter-individual variability in age at death (Shkolnikov et al. 2003: 306) and rectangularization of the survival curve (Wilmoth/ Horiuchi 1999: 475) are significant determinants of the advances in mortality transition (Cheung et al. 2009; Kannisto 2000; Lynch/Brown 2001; Myers/Manton 1984; Nusselder/Mackenbach 1996; Paccaud et al. 1998; Wilmoth/Horiuchi 1999). Over the historical trends of demographic transition of developed nations, there is consensus among researchers that mortality compression is a fundamental demographic process for comprehending the progress of mortality transition (Bohk-Ewald et al. 2017; Kannisto 2000; Robine 2001; Smits/Monden 2009; Thatcher et al. 2010). While developed nations have been passing through a low mortality regime since the middle of the 20th century and have been experiencing strong mortality compression (Kannisto 2000; Thatcher et al. 2010), India, as a developing South Asian country, experienced a rapid mortality decline in 44 years between 1970 and 2013 (Arokiasamy/Yadav 2014; Bhat et al. 1995; Bhat/Navaneetham 1991; Chaurasia 2010; Navaneetham 1993; Visaria 2004). A key concern arises about how quickly and persuasively the mortality transition in India has characterized the process of mortality compression, spurred by a reduction in variability in age at death (Yadav 2013).

\subsection{Mortality transition in India}

During the last stage of mortality transition, the contours of mortality and morbidity are characterized by a low mortality and a heavier burden of chronic noncommunicable diseases (NCDs) (Omran 2005; Robine 2001). Nevertheless, with structural changes in disease patterns (Kumar 1993; Subramanian et al. 2006; Visaria 2004), India endured a dual burden of NCDs and communicable diseases (CDs). Specifical$l y$, the burden of Infectious and Parasitic Diseases for urban men and urban women declined from 27 percent and 25 percent, respectively, of total deaths in 1975 (ORG 1979: 78) to 11 percent and 10 percent, respectively, of total deaths in 2017 (ORG 2019: 72). The burden of Diseases of the Circulatory System in urban men and urban women increased from 10.7 percent and 13 percent, respectively, of total deaths in 1975 (ORG 1979: 78) to 33.7 percent and 34.3 percent, respectively, of total deaths in 2017 (ORG 2019: 26), with a significant concentration of deaths in adult and old age groups. Despite this dual burden, the rapid mortality decline in India is signifying an epidemiological transition similar to that of developed nations (Joshi et al. 2006; Yadav/Arokiasamy 2014). On the whole, the burden of deaths attributed to NCDs and CDs was as high as 63.5 percent and 26.7 percent, respectively, in 2017 (Global Burden of Disease Collaborative Network 2018). Between 1970 and 2018, the Infant Mortality Rate (IMR) was cut by two-thirds from 129 in 1970, to 80 in 1990, to 
32 per 1000 live births in 2018 (ORG 2020; RG/ 1972-2013), and adult mortality for men and women showed a decline from 358 and 330 per 1000 persons, respectively, in 1970 to 145 and 228 per 1000 persons, respectively, in 2010 (Rajaratnam et al. 2010: 1709). Improvements in these mortality indicators as well as structural changes in disease pattern indicate that the current phase of mortality transition is significantly modulated through improved survival at adult and old (60 and above) ages (Horiuchi/Wilmoth 1998), despite the fact that IMR decline played a dominant role in the past in India (Bhat/Navaneetham 1991; Navaneetham 1993).

Edwards/Tuljapurkar (2005: 647) acknowledge that higher-order moments (Variance, Skewness, and Kurtosis) of distribution of age at death better demonstrate differentials in mortality and variability in age at death that contribute to the process of mortality compression than first-order moments ( $e_{0}$ or Mean) do (Aburto/van Raalte 2018; Canudas-Romo 2008; Chaurasia 2010; Cheung et al. 2009; Missov et al. 2015; Németh 2017; Shkolnikov et al. 2003; Wilmoth/Horiuchi 1999). Developed nations display a low disparity in the lifespan $\left(\mathrm{e}^{\dagger}\right)$, which is average remaining life expectancy at the ages when death occurs, and a higher threshold age, which separates early deaths from late deaths, though not restricted to old age (Zhang/Vaupe/ 2009: 726), as the characteristics of increasing homogeneity in old ages (Cheung/Robine 2007; Nusselder/Mackenbach 1996; Thatcher et al. 2010). Also, Cheung et al. (2009: 584) show that a decline in adult heterogeneity spurred mortality compression in Switzerland between 1920 and 2005. Both indicators (lifespan, threshold age) are higher in developed nations compared to developing nations (Aburto/van Raalte 2018; Bohk-Ewald et al. 2017; Vaupel et al. 2011). Indian women show an analogue threshold age value of 72.8 years compared to women in Japan, France, Switzerland, and Italy but a higher $\mathrm{e}^{\dagger}$ value of 18.2 years (Vaupe/ et al. 2011: 2, Table 1). With declining or negligible IMR, a convergence in age at death is incontrovertible as the model age at death $\left(\mathrm{M}^{*}\right.$ ) converges (Canudas-Romo 2008: 1198; Vallin/Mes/é 2004) and the variance of mortality distribution at age $0\left(\mathrm{~S}_{0}\right)$ and age $10\left(\mathrm{~S}_{10}\right)$ follows a similar trajectory (Engelman et al. 2010: 521, Fig. 1a). This development attests to multiplying homogeneity among the sub-populations over adult and old ages that expedite the progression in variability in age at death and mortality compression (Myers/Manton 1984; Vaupel et al. 1979; Vaupel et al. 1998) and thus marks the outset of an advanced or later stage of mortality transition. In this context, India has shown an impressive decline in IMR and adult mortality over time. Hence, transformation in the distribution of age at death is exemplified by its contribution to adultage and old-age mortality, which plays a crucial role in the pace of variability in age at death and mortality compression (Canudas-Romo 2008).

Studies on the association of the age pattern of mortality and its linkages with mortality transition are limited in India (Arokiasamy/Yadav 2014; Chaurasia 2010; Yadav/Arokiasamy 2014). Previous mortality studies in India dealt predominantly with changes in life expectancy and sex differentials in mortality (Bhat/Navaneetham 1991; Canudas-Romo et al. 2016; Kumar 1993; Navaneetham 1993; Singh/Ladusingh 2016; Subramanian et al. 2006; Yadav et al. 2012). It is important to comprehend the interlinkages between the transformation in the age pattern of mortality and the process of mortality transition by exploring the fundamental phenomena of mortal- 
ity compression and variability in age at death. Recognizing this theoretical gap, we investigated the progress of mortality compression and variance of age at death including variability in age at death during 44 years from 1970 to 2013 for India as a whole and its twelve biggest states for the first time. We explored (a) the level of mortality compression and variability in age at death in a high mortality regime versus a medium or a low mortality regime, and (b) the contribution of adult-age mortality and old-age mortality to mortality compression and variability in age at death in a high mortality regime versus a medium or a low mortality regime. We tested the hypothesis whether the mortality compression has become stronger with the reduction in variability in age at death over the course of the mortality transition. The specific objectives of the study are (1) to measure the concentration of deaths in a narrow interval of age at death, (2) to assess the contribution of variability in age at death, and (3) to investigate the convergence or divergence in mortality compression of different Indian states during mortality transition. Overall, the study examines the progress of mortality transition through advances in mortality compression and variability in age at death.

\section{Data and Methods}

In this study, we used multiple data sources and methods to assess the progress of mortality transition in India and its twelve biggest states, primarily by examining the process of mortality compression and variance of age at death including variability in age at death.

\subsection{Sample Registration System}

The Office of the Registrar General of India (ORGI) introduced the Sample Registration System (SRS) as a pilot scheme in the period 1964-65, and it was implemented as a full-scale system in the period 1969-70. The SRS in India is a dual record system. The baseline survey of households in sample units provides the usual resident population. Resident part-time enumerators record all births and deaths of usual residents in the sample of villages/urban blocks, and a full-time supervisor records births and deaths in the sample unit that occurred during the six-monthly retrospective survey. The unmatched and partially matched events are re-verified in the field to obtain the count of true events. This procedure leads to a quantitative assessment of the distortions in the two sets of records, and hence, it is a self-evaluating technique, which is a major advantage of SRS (ORG \& CC 2019). SRS allows comparison of estimates, as the methodology and definition of the statistics are consistent over time. Bhat (2002: 130, Table 6) demonstrates that completeness of death registration for all ages in the period 1971-80 was 94 percent and 93 percent for males and females, respectively. The completeness of death registration for females deteriorated in the period 1981-1991, which was attributed to the Indian states of Punjab, Haryana, Uttar Pradesh, and Maharashtra. Saikia et al. (2011: 76, Table 1) showed that IMR estimates from the National Family Household Survey (NFHS) were in ac- 
cord with SRS for the periods 1991-1995, 1996-2000, and 2002-2005. Yadav/Ram (2015: 114) observed birth undercount by 2-3 percent by SRS between 1991 and 2010. SRS data in India is considered most reliable regarding the death statistics.

\subsection{Construction of life tables}

We constructed new life tables for the entire period from 1970 to 2013. The main input is annual age-specific death rates (ASDR) from India's SRS for the entire reference period (RGI 2016; RGI 1972-2013). The five-year moving average of ASDR is used for the construction of period life tables for 1970-2013. A life table for a fiveyear period represents estimates for the mid-year of that interval. SRS provides abridged life tables (ORG 1986-2015) by quinquennial age groups; however, it does not provide life expectancy $\left(e_{x}\right)$ data for age groups over 70 years for the period 1970-1994. Notably, ASDR are provided up to age 70+ for the period 1970-1994 and up to age 85+ from 1995 onwards. Therefore, the construction of life tables is essential for the comparability of $e_{x}$ and other estimates based on age at death for analytical purposes. New life tables were constructed based on the methodology recommended by the United Nations (United Nations 1982; UNPD 2013). Using the last six ASDR, the Gompertz-Makeham (GM) model (Gompertz 1825; Juckett) Rosenberg 1993; Makeham 1867) was applied to estimate the force of mortality $\left(\mu_{X}\right)$ at higher ages up to the age of 110 years. Thus, the probability of dying between age $x$ and $x+n\left(n q_{x}\right)$ was estimated up to age 110 for the construction of the life tables. The newly constructed life tables for the five-year rolling periods of 1970 2013 were based on this methodology. These new life tables provided life table deaths between age $x$ and $x+n\left(n d_{x}\right)$ up to age 110, which was the base parameter for examining the process of mortality compression and variability in age at death (Canudas-Romo 2008; Kannisto 2000).

\subsection{Single-year distribution of age at death}

The distribution of age at death for India was bimodal during the 1970s. One of the two peaks was in the 0-1 age group, and another was in the 70-79 age group. In less than 20 years, the IMR declined swiftly and, hence, by the mid-1980s the age at death was unimodal: the peak only exists in old age groups (Arokiasamy/Yadav 2014: 11, Fig. 3). In such conditions, researchers prefer to eliminate the effect of infant and adolescent mortality in order to test mortality compression (Kannisto 2000; Nusselder/Mackenbach 1996; Robine 2001). The life table deaths for age groups 10 and above $\left({ }_{5} d_{x}: x \geq 10\right)$ were disaggregated into single year life table deaths using the Karup-King third-difference formula. This interpolation method assumes that the distribution pattern of grouped data is a valid indication of the distribution pattern within groups, maintaining the original data and the group totals at the cost of less smoothness (Popoff/Judson 2004: 696, 702). Applying this method, we derived single-year distribution of age at death between 10 and 110 years which was smoothened using the cubic spline method (Cheung et al. 2009; Kostaki/Panousis 2001). Henceforth, the single-year, smoothened distribution of age at death between 
10 and 110 years is referred to as the distribution of age at death or age at death which was used to examine mortality compression and variability in age at death.

\subsection{Methodology for mortality compression and variability in age at death}

We adopted and computed the following mortality compression measures: modal age at death $\left(\mathrm{M}^{*}\right)$, standard deviation (SD) for age 10 and older $(\mathrm{SD}(10+))$, between the age 10 and below $\mathrm{M}^{*}\left(\mathrm{SD}\left(<\mathrm{M}^{*}\right)\right)$, for age $\mathrm{M}^{*}$ and older $\left(\mathrm{SD}\left(\mathrm{M}^{*}+\right)\right)$ (CanudasRomo 2008; Kannisto 2001; Thatcher et al. 2010), and C50 (C-family) (Kannisto 2000: see Annex), which is the best known measure for computing the concentration of 50 percent of life table deaths in a narrow age interval of age at death.

Mathematically, the SD about $\mathrm{M}^{*}$ for distribution of age at death is an absolute measure, which is expressed as:

$$
S D\left(M^{*}(t)\right)=\sqrt[2]{\frac{\int_{\int_{a}^{W-1}\left\{x-\left(M^{*}(t)\right)\right\}^{2} * d(x, t) d x}^{\int_{a}^{W-1} d(x, t) d x}}{x^{2}}}
$$

where, $\mathrm{M}^{*}$ : modal age at death; $t$ : time (year); a: initial age; $w$ : oldest age; $x$ : age; $d$ : deaths at age $x$.

Similarly,

$$
\begin{aligned}
& S D\left(<M^{*}(t)\right)=\sqrt[2]{\frac{\int_{a}^{M^{*}}\left\{x-\left(M^{*}(t)\right)\right\}^{2} * d(x, t) d x}{\int_{a}^{M^{*}} d(x, t) d x}} \\
& S D\left(M^{*}+(t)\right)=\sqrt[2]{\frac{\int_{M^{*}}^{w-1}\left\{x-\left(M^{*}(t)\right)\right\}^{2} * d(x, t) d x}{\int_{M^{*}}^{w-1} d(x, t) d x}} \\
& S D(10+(t))=\sqrt[2]{\frac{\int_{10}^{w-1}\left\{x-\left(M^{*}(t)\right)\right\}^{2} * d(x, t) d x}{\int_{10}^{w-1} d(x, t) d x}}
\end{aligned}
$$

We applied the Gini coefficient at age $10\left(\mathrm{G}_{10}\right)$ to compute the variability in age at death (Shkolnikov et al. 2003) based on the newly constructed abridged life tables. The Gini coefficient at age 10 for an abridged life table is expressed as:

$$
G_{10}(t)=1-\frac{1}{e_{10} *\left[l_{10}\right]^{2}} \sum_{x=10}^{w-1} n *\left[\left(l_{x+n}\right)^{2}+\hat{a}_{x}\left(\left(l_{x}\right)^{2}-\left(l_{x+n}\right)^{2}\right)\right]
$$


where,

$\hat{a}_{x}\left[=\frac{\left(\frac{{ }_{n} L_{x}}{n}\right)-l_{x+n}}{\left(l_{x}-l_{x+n}\right)}\right] \begin{aligned} & \text { : adjusted average person-years lived by the individuals who } \\ & \text { die within the interval } I_{x}-I_{x+n} ; w \text { : oldest age; } I_{x}: \text { person-years } \\ & \text { lived at age } x ; n \text { : age interval. }\end{aligned}$

The application of decomposition technique for $\mathrm{G}_{10}$ was based on standardization of ASDR. The decomposition technique is applied over the permutations of populations and time, running from age 10 to the oldest age, for computing the agespecific contributions to $\mathrm{G}_{10}$. It is expressed as

$$
\delta_{i}=e_{10}\left(M^{\left[x_{i}+n\right]}\right)-e_{10}\left(M^{\left[x_{i}\right]}\right)
$$

where, $\delta_{i}$ is the contribution of $j$ th age-interval $[x, x+n)$ to the difference in $\mathrm{e}_{10}$ between two populations, $M^{\left[x_{i}\right]}$ is a vector of age-specific mortality rates with its elements in the first population for $x \leq x_{i}$ and in the second population for $x \geq x_{i}$ (Shkolnikov et al. 2003: 325).

We applied beta convergence, i.e. a negative relationship between the change of an estimate in a period and the level of the estimate in the initial period, and sigma convergence, i.e. decline in the dispersion of mortality distribution (Barro/Sala i Martin 1990; Janssen et al. 2016) to test the process of convergence in C50. Beta convergence was carried out by regressing the annual change in $\mathrm{C} 50$ in the period $t_{0}$ to $t_{1}$ with $\mathrm{C} 50$ in $t_{0}$ for India.

Statistically,

$$
\left(\frac{1}{t}\right) *\left(C 50\left(t_{1}\right)-C 50\left(t_{0}\right)\right)=\alpha+\beta\left(t_{0}\right) * C 50\left(t_{0}\right)+\varepsilon
$$

where, C50: concentration of 50 percent of deaths in an age interval of age at death; $t_{0}$ : the initial year (the period 1970-1974); $t_{1}$ : the end year (the period 2009-2013); $\alpha$ : constant, $\beta$ : the slope; and $\varepsilon$ : the error term of a regression model.

Sigma convergence was executed by computing the ratio of $\mathrm{SD}\left(<\mathrm{M}^{*}\right)$ to $\mathrm{SD}(10+)$.

We define the ratio $r_{s}(t)$ as follows:

$$
r_{s}(t)=\frac{S D\left(<M^{*}\right)}{S D(10+)}
$$

where, $r$ : ratio; $s$ : a region (Indian state).

The ratio $r_{s}(t)$ measures the proportion of variation contributed by age at death from 10 years and below the $\mathrm{M}^{*}$ about $\mathrm{M}^{*}\left(\mathrm{SD}\left(<\mathrm{M}^{*}\right)\right)$ to the total variation of age at death between 10 and 110 years about $\mathrm{M}^{*}(\mathrm{SD}(10+))$ for a region $s$ at time $t$. Demographically, the trends in $r_{s}(t)$ show the reduction in premature mortality, which is deaths between age 10 and below $\mathrm{M}^{*}$, adjusted for the shift in $\mathrm{M}^{*}$. The $r_{s}(t)$ is a relative measure which is applied to describe the progression in the variability of the selected states (regions) towards a coherent value or a limiting value over the transitional period from 1970 to 2013 . Another advantage of this ratio is its ability to identify outliers among states for a sigma convergence. From the known level of $\mathrm{e}^{\dagger}$ for developed countries (Vaupel et al. 2011), the lowest known value of $\mathrm{e}^{\dagger}$ is 9.2 for 
Japan with the highest $e_{0}$ value of 86.4 years in 2011. Given the low level of $\mathrm{e}^{\dagger}$, the value of ratio $r_{s}(t)$ would tend towards a limiting value for Japan. In the condition of minimum premature mortality or low mortality condition, a normal curve about $\mathrm{M}^{*}$ is evident (Lexis 1877 as cited in Kannisto (2000: 159-160)). At this stage, variability in age at death would be minimal, and the $r_{s}(t)$ would approach the value of 1.0.

\subsection{Validating model fit and life table estimates}

We fitted the GM model over ASDR to estimate ${ }_{n} q_{x}$ in old age up to 110 years (Carey et al. 1992; Vaupel et al. 1998), assuming ${ }_{n} q_{x}$ follows an exponential curve. The Levenberg-Marquardt (LM) algorithm for a non-linear regression method was used for optimizing the parameters of the GM model because it interpolates between the Gauss-Newton algorithm and the method of gradient descent (Ibrahim 2008: 4) and thus provides balanced estimates of model parameters. The Gompertz model or Law of Mortality is universal for all populations; however, Carey et al. (1992) raise doubts regarding the central concept of gerontology, especially the heterogeneity $(\gamma)$ of the study population. The GM model: $\mu_{x}=c+a b^{x}$; where $x \geq 35, a>0, b>1$, $c \geq-a$ (Makeham 1867) takes into account the non-zero extrinsic mortality or assumes hazard $c$ at all ages $x$ in addition to $a$ and $b$ which are death rate at initial age and slope of mortality increase, respectively. However, it does not account for the heterogeneity in the population. In that case, the GM model may lead to biases of model parameters (Missov/Németh 2015: 117, 118). The gamma GM model accounts for deceleration in mortality rates at older ages and shows a better fit compared to the logistic model (Bongaarts 2005: 25, Fig. 1; Missov/Németh 2015: 118, Fig. 2). However, despite these constraints, the mortality measures like life expectancy, life disparity, entropy, and the Gini coefficient are only slightly sensitive to model misspecification. Therefore, Gompertz family is most suitable and beneficial for studying human mortality data. Modal age at death is a measure that is deemed to be sensitive to model misclassification (Missov/Németh 2015: 130, Fig. 5).

We applied the GM model for India because mortality data are aggregated for the population and, thus, heterogeneity $(\gamma)$ in the population is unobserved. It may be noted that there has been some contention among Indian demographers over the success of applying the Gompertz family to the Indian populations. Saikia et al. (2011: 78, Fig. 2) show that the Gompertz model did not fit well for the periods 1981-1985 and 2000-2004, and hence mortality estimates in old ages for India were called into doubt. However, we confirm that the GM model fitted well over ASDR for India for the entire period of 1970-2013, satisfying the conditions of the parameters of the model. Therefore, the mortality estimates in old ages are robust enough (Lee 2003). The fit of the GM model over the ASDR from age 35 is significant at the one percent level (Table 1, 2, and Fig. 1). The proportion of the variance explained by the GM model averages out at 0.9769 and 0.9678 for women and men, respectively, for the period 1970-2013. The slope $b$ of the GM model for men and women remained nearly constant from 1970 through to 2013 (Table 1, 2 (last column)) and therefore depicts shifting of mortality rates in old ages (Horiuchi/Wilmoth 1998) (Fig. 1) similar to those of men and women in developed nations (Bongaarts 2005: 27, Fig. 2, 28, 
Tab. 1: Parameters of the Gompertz-Makeham model, Indian women, 19702013

\begin{tabular}{|c|c|c|c|}
\hline Year & a & c & b \\
\hline $1970-1974$ & 0.0179497 & 0.0002530 & 1.1129957 \\
\hline 1971-1975 & 0.0181967 & 0.0002552 & 1.1136880 \\
\hline $1972-1976$ & 0.0177643 & 0.0002380 & 1.1151444 \\
\hline 1973-1977 & 0.0161678 & 0.0002488 & 1.1139609 \\
\hline 1974-1978 & 0.0137552 & 0.0003159 & 1.1096285 \\
\hline 1975-1979 & 0.0128564 & 0.0003301 & 1.1083128 \\
\hline 1976-1980 & 0.0124846 & 0.0002966 & 1.1091272 \\
\hline 1977-1981 & 0.0118703 & 0.0003035 & 1.1083241 \\
\hline 1978-1982 & 0.0119633 & 0.0002858 & 1.1081265 \\
\hline 1979-1983 & 0.0118245 & 0.0002577 & 1.1093404 \\
\hline $1980-1984$ & 0.0113718 & 0.0002480 & 1.1101719 \\
\hline 1981-1985 & 0.0100052 & 0.0002965 & 1.1069923 \\
\hline 1982-1986 & 0.0108660 & 0.0002380 & 1.1106573 \\
\hline 1983-1987 & 0.0099030 & 0.0002444 & 1.1102394 \\
\hline 1984-1988 & 0.0092907 & 0.0002413 & 1.1103814 \\
\hline 1985-1989 & 0.0091276 & 0.0002172 & 1.1116056 \\
\hline $1986-1990$ & 0.0094232 & 0.0001662 & 1.1160647 \\
\hline 1987-1991 & 0.0092275 & 0.0001597 & 1.1164004 \\
\hline 1988-1992 & 0.0102529 & 0.0001335 & 1.1195324 \\
\hline 1989-1993 & 0.0098395 & 0.0001362 & 1.1187246 \\
\hline $1990-1994$ & 0.0094743 & 0.0001533 & 1.1162522 \\
\hline 1991-1995 & 0.0088546 & 0.0001803 & 1.1128260 \\
\hline 1992-1996 & 0.0072246 & 0.0002445 & 1.1071916 \\
\hline 1993-1997 & 0.0050294 & 0.0003167 & 1.1026522 \\
\hline 1994-1998 & 0.0047142 & 0.0003328 & 1.1018568 \\
\hline 1995-1999 & 0.0030074 & 0.0003922 & 1.0992254 \\
\hline $1996-2000$ & 0.0016532 & 0.0004423 & 1.0972138 \\
\hline $1997-2001$ & 0.0004362 & 0.0005011 & 1.0948280 \\
\hline $1998-2002$ & 0.0013839 & 0.0005513 & 1.0931025 \\
\hline $1999-2003$ & 0.0021177 & 0.0005653 & 1.0921804 \\
\hline $2000-2004$ & 0.0003725 & 0.0004370 & 1.0956443 \\
\hline 2001-2005 & 0.0005823 & 0.0004084 & 1.0965212 \\
\hline $2002-2006$ & 0.0001576 & 0.0003382 & 1.0993023 \\
\hline $2003-2007$ & 0.0013817 & 0.0002708 & 1.1025866 \\
\hline $2004-2008$ & 0.0018518 & 0.0002299 & 1.1050549 \\
\hline $2005-2009$ & 0.0000082 & 0.0002573 & 1.1038210 \\
\hline $2006-2010$ & 0.0002451 & 0.0002570 & 1.1037615 \\
\hline $2007-2011$ & 0.0005430 & 0.0002391 & 1.1046662 \\
\hline 2008-2012 & 0.0004830 & 0.0002419 & 1.1042331 \\
\hline $2009-2013$ & 0.0010027 & 0.0002338 & 1.1043491 \\
\hline
\end{tabular}

Source: Own calculations using ASDR (RG/ 1972-2013); $\mu_{x}=c+a b^{x}, x$ is age; the parameter $a, c$, and $b$ are all significant at the one percent level for each year. 
Tab. 2: $\quad$ Parameters of the Gompertz-Makeham model, Indian men, 1970-2013

\begin{tabular}{|c|c|c|c|}
\hline Year & a & c & b \\
\hline $1970-1974$ & 0.00169 & 0.00133 & 1.08872 \\
\hline 1971-1975 & 0.00464 & 0.00109 & 1.09209 \\
\hline 1972-1976 & 0.00196 & 0.00132 & 1.08946 \\
\hline 1973-1977 & 0.00127 & 0.00146 & 1.08734 \\
\hline 1974-1978 & 0.00016 & 0.00153 & 1.08668 \\
\hline $1975-1979$ & 0.00168 & 0.00169 & 1.08442 \\
\hline $1976-1980$ & 0.00016 & 0.00135 & 1.08805 \\
\hline 1977-1981 & 0.00350 & 0.00100 & 1.09239 \\
\hline 1978-1982 & 0.00391 & 0.00083 & 1.09494 \\
\hline 1979-1983 & 0.00618 & 0.00065 & 1.09859 \\
\hline 1980-1984 & 0.00679 & 0.00056 & 1.10126 \\
\hline 1981-1985 & 0.00290 & 0.00085 & 1.09392 \\
\hline 1982-1986 & 0.00205 & 0.00089 & 1.09282 \\
\hline 1983-1987 & 0.00170 & 0.00092 & 1.09234 \\
\hline 1984-1988 & 0.00192 & 0.00088 & 1.09290 \\
\hline 1985-1989 & 0.00258 & 0.00080 & 1.09425 \\
\hline $1986-1990$ & 0.00467 & 0.00064 & 1.09767 \\
\hline 1987-1991 & 0.00421 & 0.00062 & 1.09793 \\
\hline 1988-1992 & 0.00508 & 0.00057 & 1.09937 \\
\hline 1989-1993 & 0.00364 & 0.00064 & 1.09713 \\
\hline 1990-1994 & 0.00329 & 0.00068 & 1.09576 \\
\hline 1991-1995 & 0.00343 & 0.00067 & 1.09557 \\
\hline 1992-1996 & 0.00435 & 0.00064 & 1.09614 \\
\hline 1993-1997 & 0.00126 & 0.00085 & 1.09144 \\
\hline 1994-1998 & 0.00021 & 0.00092 & 1.09021 \\
\hline 1995-1999 & 0.00026 & 0.00097 & 1.08890 \\
\hline $1996-2000$ & 0.00203 & 0.00116 & 1.08605 \\
\hline $1997-2001$ & 0.00329 & 0.00128 & 1.08428 \\
\hline 1998-2002 & 0.00336 & 0.00129 & 1.08376 \\
\hline $1999-2003$ & 0.00249 & 0.00125 & 1.08377 \\
\hline $2000-2004$ & 0.00102 & 0.00103 & 1.08656 \\
\hline 2001-2005 & 0.00104 & 0.00083 & 1.08961 \\
\hline $2002-2006$ & 0.00259 & 0.00069 & 1.09214 \\
\hline $2003-2007$ & 0.00469 & 0.00054 & 1.09589 \\
\hline 2004-2008 & 0.00659 & 0.00045 & 1.09872 \\
\hline $2005-2009$ & 0.00534 & 0.00049 & 1.09766 \\
\hline $2006-2010$ & 0.00476 & 0.00053 & 1.09649 \\
\hline 2007-2011 & 0.00433 & 0.00055 & 1.09574 \\
\hline $2008-2012$ & 0.00269 & 0.00066 & 1.09279 \\
\hline $2009-2013$ & 0.00470 & 0.00053 & 1.09583 \\
\hline
\end{tabular}

Source: Own calculations using ASDR (RG/ 1972-2013); $\mu_{x}=c+a b^{x}, x$ is age; the parameter $a, c$, and $b$ are all significant at the one percent level for each year. 
Fig. 1: Gompertz-Makeham (GM) fit for selected years for India, by sex

(a) Women, SRS

$\mathrm{LN}$ of Force of Mortality (nMx)

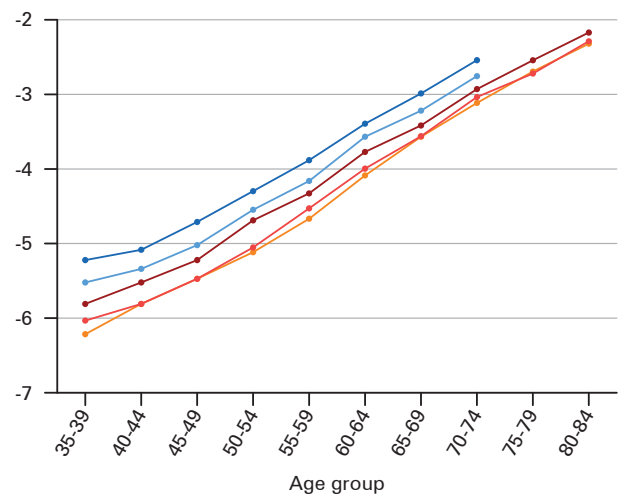

(b) Women, GM

LN of Force of Mortality (nMx)

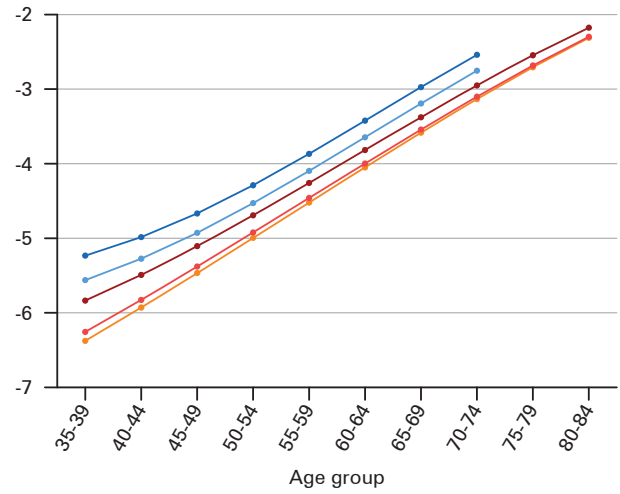

——1973-1977

$\longrightarrow$ 1983-1987

— 1993-1997

LN of Force of Mortality ( $\mathrm{nMx}$ )

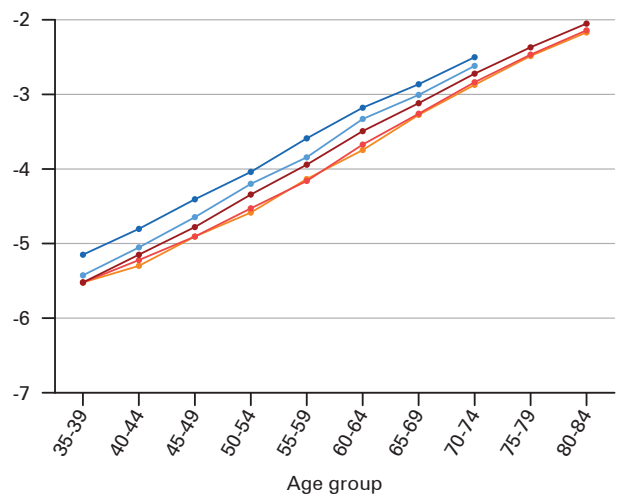

(d) Men, GM

LN of Force of Mortality ( $\mathrm{nMx}$ )

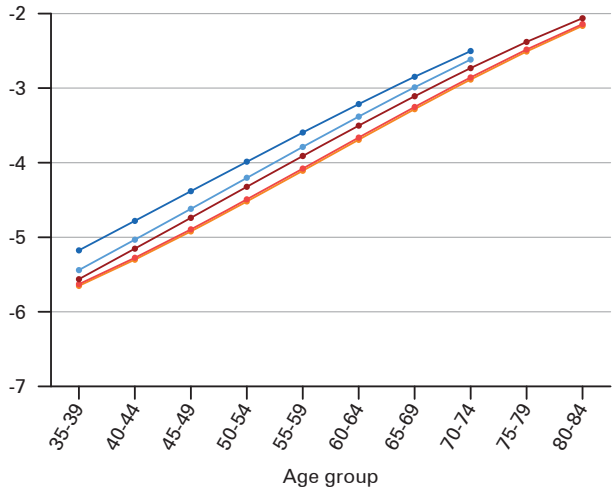

Age group

Note: Mortality rate is shown per person.

Source: Own calculations using ASDR (RG/ 1972-2013)

Fig 3, panel b). The differences in life expectancy at age $50\left(e_{50}\right)$ and life expectancy at age $60\left(\mathrm{e}_{60}\right)$ between SRS and our own calculations are minimal, which is shown in Table 3 for the five-year intercensal periods.

Lastly, we conducted analyses for India as a whole and its twelve biggest states by sex and residence for the rolling five-year periods between 1970 and 2013, the critical period that represented India's transition from a high to a medium and to a low mortality regime. The twelve biggest states included are Andhra Pradesh, Gujarat, Karnataka, Kerala, Maharashtra, Punjab, Tamil Nadu (pioneer Indian states), Assam, Haryana, Madhya Pradesh, Odisha, and Uttar Pradesh (backward Indian states) (see Table 4). 
Tab. 3: Life expectancy $\left(e_{x}\right)$ at age 50 and 60 for selected years, by sex, 19702013

\begin{tabular}{lcccccccc}
\hline Year & \multicolumn{3}{c}{ Women } & \multicolumn{3}{c}{ Men } \\
& \multicolumn{2}{c}{$\mathrm{e}_{50}$} & \multicolumn{2}{c}{$\mathrm{e}_{60}$} & \multicolumn{2}{c}{$\mathrm{e}_{50}$} & \multicolumn{2}{c}{$\mathrm{e}_{60}$} \\
& SRS & Estimate & SRS & Estimate & SRS & Estimate & SRS & Estimate \\
\hline $1970-1975$ & 21.3 & 21.3 & 14.3 & 14.2 & 19.8 & 19.9 & 13.4 & 13.5 \\
$1976-1980$ & 23.0 & 22.0 & 15.9 & 14.7 & 20.5 & 20.1 & 14.1 & 13.7 \\
$1981-1985$ & 23.8 & 23.0 & 16.4 & 15.6 & 21.4 & 21.1 & 14.6 & 14.2 \\
$1986-1990$ & 23.7 & 23.5 & 16.1 & 15.8 & 21.7 & 21.6 & 14.7 & 14.6 \\
$1991-1995$ & 24.8 & 24.3 & 17.1 & 16.5 & 22.3 & 22.2 & 15.3 & 15.1 \\
$1996-2000$ & 25.5 & 25.2 & 17.8 & 17.5 & 22.8 & 22.7 & 15.8 & 15.7 \\
$2001-2005$ & 26.7 & 26.5 & 18.7 & 18.4 & 23.7 & 23.7 & 16.4 & 16.4 \\
$2002-2006$ & 26.9 & 26.6 & 18.9 & 18.5 & 24.0 & 23.9 & 16.7 & 16.5 \\
$2009-2013$ & 27.2 & 26.7 & 19.0 & 18.9 & 24.2 & 24.0 & 16.9 & 16.8 \\
\hline
\end{tabular}

Source: Own calculations using ASDR (RG/ 1972-2013)

\section{$3 \quad$ Results}

\subsection{Age pattern of mortality and premature mortality}

Figure 2 illustrates the transformation in age patterns of mortality for women and men by residence between 1970 and 2013, signifying a significant period of mortality transition in India. A flattening age pattern of mortality - across all ages - is evident, and it is most prominent for rural women compared to other population categories. Only in the infant, child, and adolescent ages do rural and urban women now have a higher ${ }_{n} q_{x}$; otherwise, women aged 25 and older have a lower ${ }_{n} q_{x}$ compared to men. The ${ }_{30} q_{15}$ for rural women (Fig. 2a) and rural men (Fig. 2c) declined by a rate (CAGR) of -2.2 and -1.1 percentage points per year, respectively, in the transitional period. The swift decline of $30 q_{15}$ for women reflects a sharp decline in mortality in childbearing ages. Overall, reshaping of the age pattern of mortality in India took a relatively short time, i.e. the last two decades of the 1990s and 2000s. The first of the two components that contributed to this transformation is the decline in the IMR since the 1970s, and the second is the decline in young adult mortality $\left(30 q_{15}\right)$ since the 1990s. Therefore, infant mortality together with young adult mortality decline indicate an improvement in the chances of survival in India.

In principle, the comparison of mortality rates contains the same information as the comparison of mortality distribution (Edwards/Tuljapurkar 2005: 670). The structural changes in the pattern of causes of death immensely contributed to the transformation in age at death leading to the concentration of death in old ages (Yadav/Arokiasamy 2014: Fig. 2 and 3). The shift in the concentration of deaths attributable to Certain Infectious and Parasitic Diseases for urban women in the 0-4 age group and 65 plus age group was from 38 percent and 5.6 percent, respectively, in 1975 (ORG 1979: 78) to 8.9 percent and 23.6 percent, respectively, in 2013 (ORG 2015). The toll of deaths attributable to Certain Infectious and Parasitic Diseases 
Tab. 4: Annual estimates of Birth rate, Death rate, IMR, and TFR for selected States, India, by residence, 1971 and 2013

\begin{tabular}{|c|c|c|c|c|c|c|c|c|c|c|}
\hline \multirow[t]{2}{*}{ States } & \multirow[t]{2}{*}{ Region } & \multirow[t]{2}{*}{ Category } & \multicolumn{4}{|c|}{1971} & \multicolumn{4}{|c|}{2013} \\
\hline & & & $\begin{array}{l}\text { Birth } \\
\text { Rate }\end{array}$ & $\begin{array}{c}\text { Death } \\
\text { Rate }\end{array}$ & IMR & TFR & $\begin{array}{l}\text { Birth } \\
\text { Rate }\end{array}$ & $\begin{array}{c}\text { Death } \\
\text { Rate }\end{array}$ & IMR & TFR \\
\hline \multicolumn{11}{|c|}{ Rural } \\
\hline India & - & - & 38.9 & 16.4 & 138 & 5.4 & 22.9 & 7.5 & 44 & 2.5 \\
\hline Andhra Pradesh & South & $\mathrm{P}$ & 35.6 & 15.7 & 115 & 4.8 & 17.7 & 8.3 & 44 & 1.9 \\
\hline Assam & Northeast & B & 39.3 & 18.7 & 144 & 5.8 & 23.5 & 8.2 & 54 & 2.3 \\
\hline Gujarat & West & $\mathrm{P}$ & 41.5 & 17.6 & 155 & 5.9 & 22.2 & 7.2 & 43 & 2.5 \\
\hline Haryana & North & B & 44.2 & 10.4 & 74 & 7.3 & 22.4 & 6.7 & 44 & 2.3 \\
\hline Karnataka & South & $P$ & 34.6 & 14.0 & 105 & 4.8 & 19.1 & 8.0 & 34 & 2.0 \\
\hline Kerala & South & $P$ & 31.3 & 9.1 & 60 & 4.2 & 15.0 & 7.0 & 13 & 1.9 \\
\hline Madhya Pradesh & Central & B & 40.0 & 16.6 & 144 & 6.1 & 28.2 & 8.5 & 57 & 3.1 \\
\hline Maharashtra & West & $\mathrm{P}$ & 33.7 & 13.5 & 111 & 4.9 & 17.2 & 7.1 & 29 & 1.9 \\
\hline Odisha & East & B & 34.7 & 15.9 & 131 & 4.8 & 20.5 & 8.7 & 53 & 2.2 \\
\hline Punjab & North & $\mathrm{P}$ & 35.0 & 10.9 & 109 & 5.5 & 16.3 & 7.5 & 28 & 1.7 \\
\hline Tamil Nadu & South & $P$ & 32.9 & 16.5 & 127 & 4.2 & 15.7 & 8.1 & 24 & 1.7 \\
\hline Uttar Pradesh & Central & B & 46.3 & 21.1 & 173 & 6.9 & 28.1 & 8.1 & 53 & 3.3 \\
\hline \multicolumn{11}{|c|}{ Urban } \\
\hline India & - & - & 30.1 & 9.7 & 82 & 4.1 & 17.3 & 5.6 & 27 & 1.8 \\
\hline Andhra Pradesh & South & B & 31.3 & 9.1 & 65 & 3.8 & 16.7 & 5.0 & 29 & 1.7 \\
\hline Assam & Northeast & $\mathrm{P}$ & 31.0 & 9.5 & 73 & 4.3 & 15.4 & 5.6 & 32 & 1.5 \\
\hline Gujarat & West & B & 35.8 & 13.0 & 110 & 4.7 & 18.5 & 5.5 & 22 & 2.0 \\
\hline Haryana & North & $\mathrm{P}$ & 43.4 & 7.3 & 58 & 4.6 & 19.0 & 5.3 & 32 & 2.0 \\
\hline Karnataka & South & $\mathrm{P}$ & 25.3 & 7.2 & 54 & 3.4 & 16.7 & 5.2 & 24 & 1.6 \\
\hline Kerala & South & B & 29.6 & 8.4 & 48 & 3.8 & 14.0 & 6.6 & 9 & 1.8 \\
\hline Madhya Pradesh & Central & $\mathrm{P}$ & 34.5 & 9.8 & 79 & 4.7 & 19.6 & 6.1 & 37 & 2.0 \\
\hline Maharashtra & West & B & 29.0 & 9.7 & 88 & 3.9 & 15.4 & 5.0 & 16 & 1.6 \\
\hline Odisha & East & $\mathrm{P}$ & 33.0 & 10.0 & 84 & 4.3 & 14.4 & 6.3 & 38 & 1.5 \\
\hline Punjab & North & $\mathrm{P}$ & 31.4 & 8.7 & 76 & 4.4 & 14.7 & 5.4 & 23 & 1.6 \\
\hline Tamil Nadu & South & B & 27.8 & 9.3 & 77 & 3.3 & 15.5 & 6.3 & 17 & 1.7 \\
\hline Uttar Pradesh & Central & $P$ & 34.7 & 13.1 & 119 & 4.9 & 23.3 & 5.9 & 38 & 2.5 \\
\hline
\end{tabular}

Note: The pioneer $(\mathrm{P})$ and backward $(\mathrm{B})$ states are categorized on the basis of death rate, birth rate, and IMR in the period 1993-1997

Source: $R G /$ (2016: Table 1)

turned upside down from child to old age groups during 39 years between 1975 and 2013. Since the mid-1990s the country has experienced enormous rise in the burden of chronic NCDs which intruded in the later years of life. The high concentration of deaths of 21 percent and 63 percent, attributable to the Diseases of the Circulatory system, among urban men in the 25-44 and 45-64 age groups, respectively, in 1975 gradually shifted to older age groups, with 36.3 percent and 45.6 percent, respectively, in the 45-64 and 65 plus age groups, in 2013 (ORG 1979; ORG 2015). A similar shift in concentration of deaths was evident for other population categories (Yadav) 
Fig. 2: $\quad$ Probability of dying for selected years for India, by population category

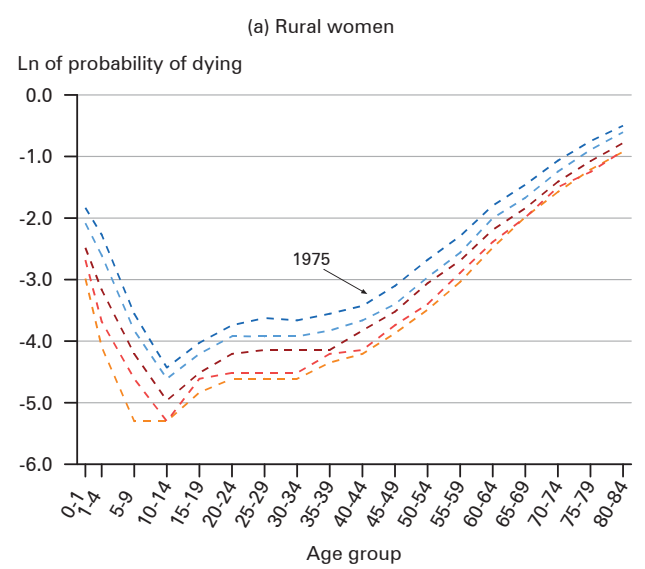

(b) Urban Women

Ln of probability of dying

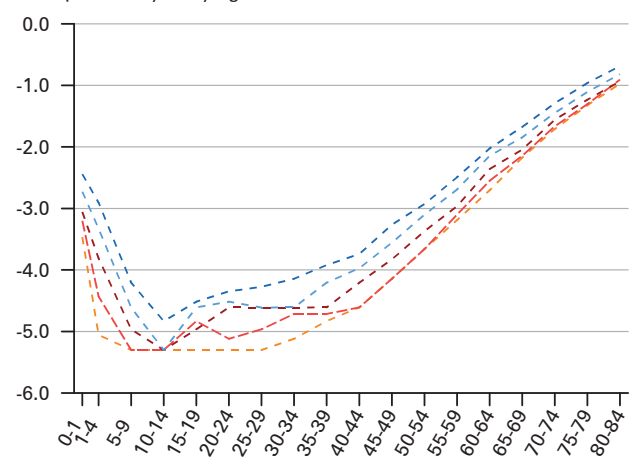

Age group

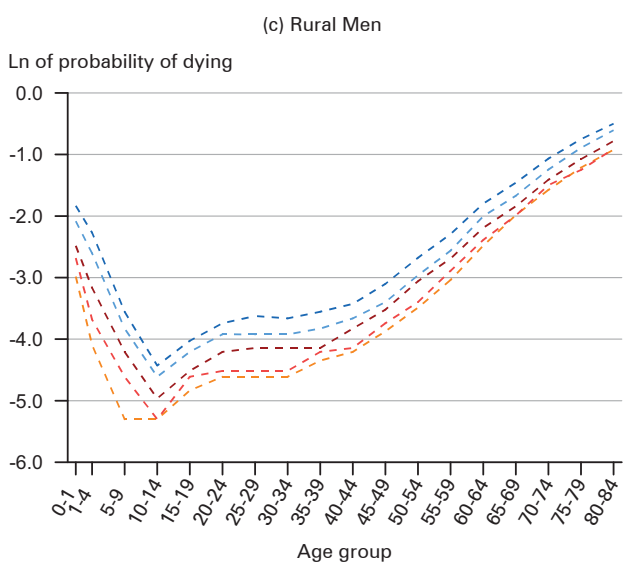

(d) Urban Men

Ln of probability of dying

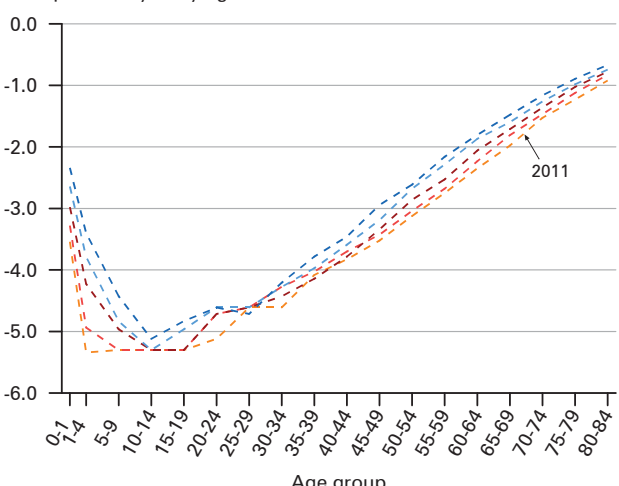

- - - - - - - - 1973-1977 - 1993-1987 - 2009-2013

Note: The years 1975 and 2011 in the above graph represents the periods 1973-1977 and 2009-2013, respectively.

Source: Own calculations using ASDR (RG/ 1972-2013)

Arokiasamy 2014: Fig. 4 and 5). The high concentration of deaths at adult and old ages was attributable to the prodigious rise of NCDs as well as the structural shift of CDs.

The distribution of age at death characterized by an increasing concentration of deaths about $\mathrm{M}^{*}$ shifting to older ages demonstrated a greater reduction in premature mortality between the age of 10 and below $M^{*}$ (Kannisto 2001) in the transitional period from 1970 to 2013, and was especially conspicuous for women (Fig. 3A and 3B: $c$ and d) compared to men (Fig. 3A and 3B: $a$ and b). The upsurge in the bellshaped distribution of age at death about $\mathrm{M}^{*}$ points to increasing homogeneity in older ages. The $\mathrm{M}^{*}$ for urban women and rural women increased respectively from 75 and 73 years to 78 and 81 years, remaining higher than that of men throughout 
Fig. 3A: Premature mortality for Rural India, 1973-1977 and 2003-2007, by sex
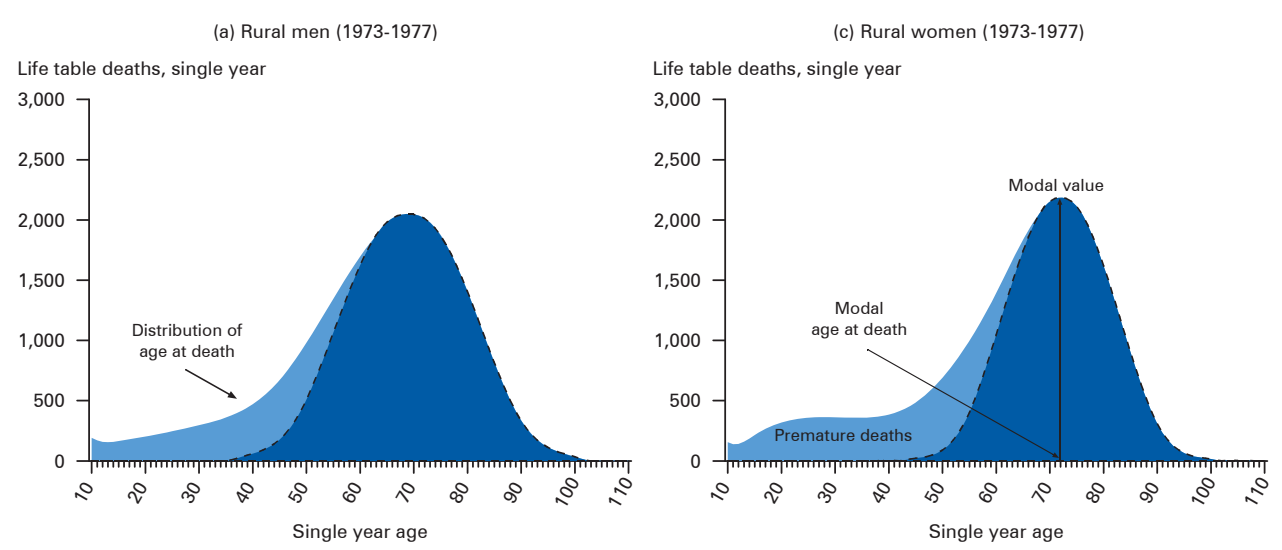

(b) Rural men (2003-2007)

(d) Rural women (2003-2007)
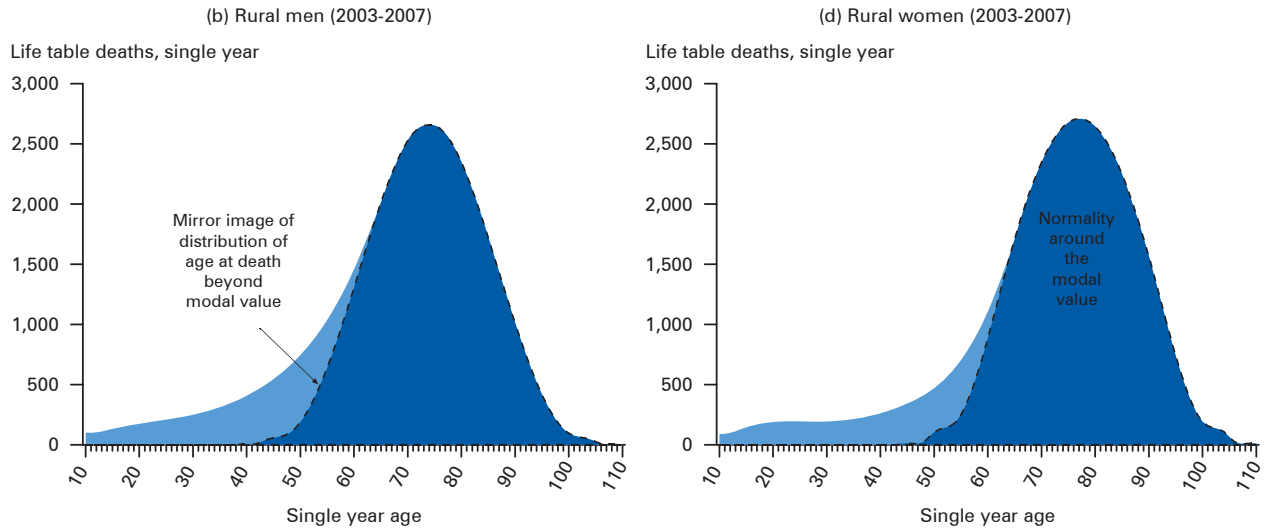

Source: Own calculations

the transitional period (Fig. 4). Developed nations have shown convergence in $\mathrm{M}^{*}$ (Canudas-Romo 2008; Thatcher et al. 2010) whereas the developing country India showed a linear increase in $\mathrm{M}^{*}$ which lags by 10 years for women and 8 years for men (Yadav/Arokiasamy 2014: Fig. 8). Although India lags behind the developed nations in mortality transition, the distribution of age at death has been reshaped into a more left-skewed distribution (Fig. 5) similar to that of developed nations (Cheung/ Robine 2007: 88, Fig. 2; Kannisto 2000: Fig. 6). This development has been faster since the 1990s, basically because young adult mortality exhibited a rapid decline, leading to a period that can be termed as a phenomenal phase of mortality transition in India.

\subsection{Mortality compression in India}

Figure 6 depicts the trends in C50 by residence and sex for India between 1970 and 2013. First, the C50 values for India declined in all population categories. Sorted 
Fig. 3B: Premature mortality for Urban India, 1973-1977 and 2003-2007, by sex
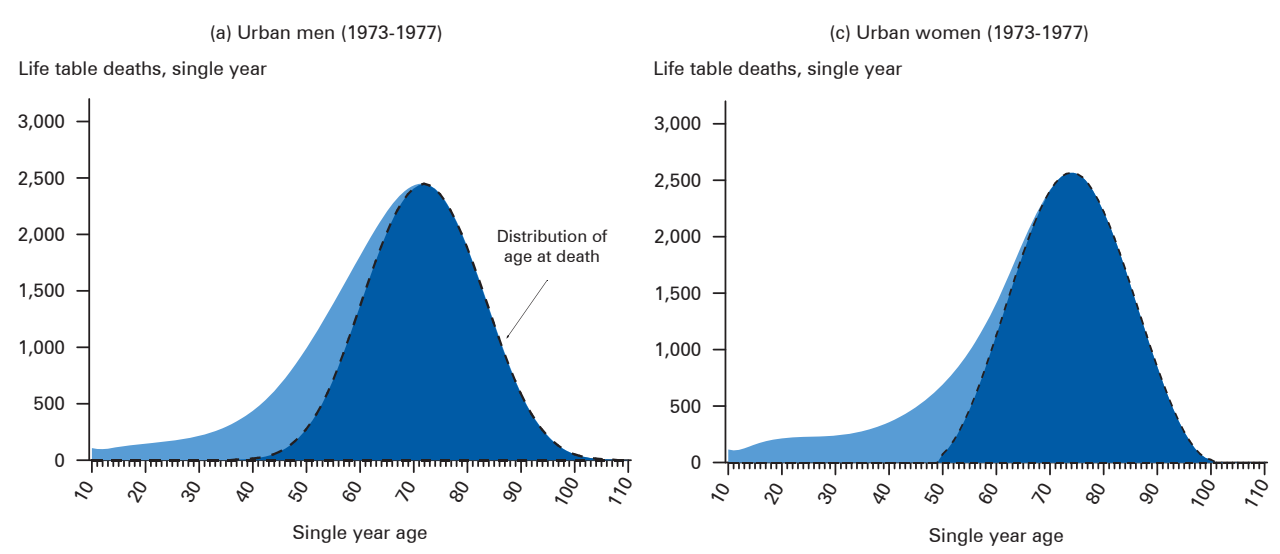

(b) Urban men (2003-2007)
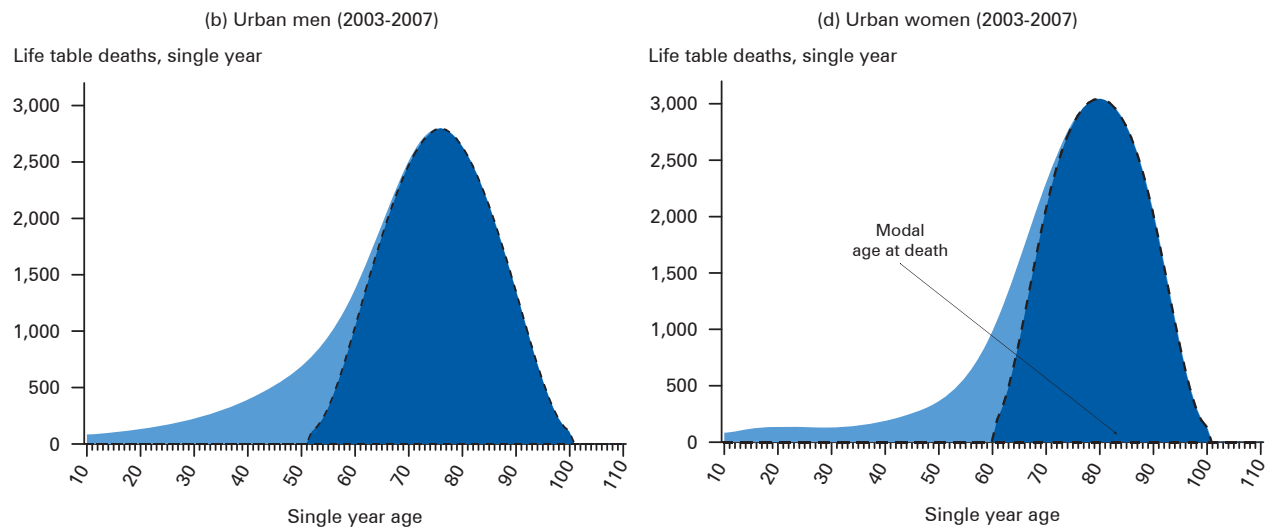

Source: Own calculations

by population category, women living in urban areas had the narrowest $\mathrm{C} 50$ values throughout the transitional period. The $\mathrm{C} 50$ values for urban women and men declined from 23.4 and 24.0 years in the period $1970-1974$ to 17.3 and 19.7 years in the period 2009-2013, respectively. Urban population had narrower C50 values throughout the transitional period than their rural counterparts. The declining C50 values reveal that deaths have been increasingly concentrated in a narrower age interval of age at death during the transition from high to low mortality conditions.

Second, the C50 values declined at a faster pace in the 1970s and 1980s, with the fastest pace for the rural population when sorted by population category. Women living in rural areas showed six years decline in C50 from 28 years in early 1970s to 22 years in the late 1980 s, outstripping men living in rural areas in the early 1980s. Concerning the rural population, the deaths were dispersed over a wider age interval of age at death during the 1970s but swiftly concentrated in a narrower age interval of age at death by the end of the 1980s. Here, rural women showed a narrower age interval of age at death which was slightly wider than that of urban 
Fig. 4: Trends in modal age at death for India, 1970-2013, by sex and residence Modal age at death

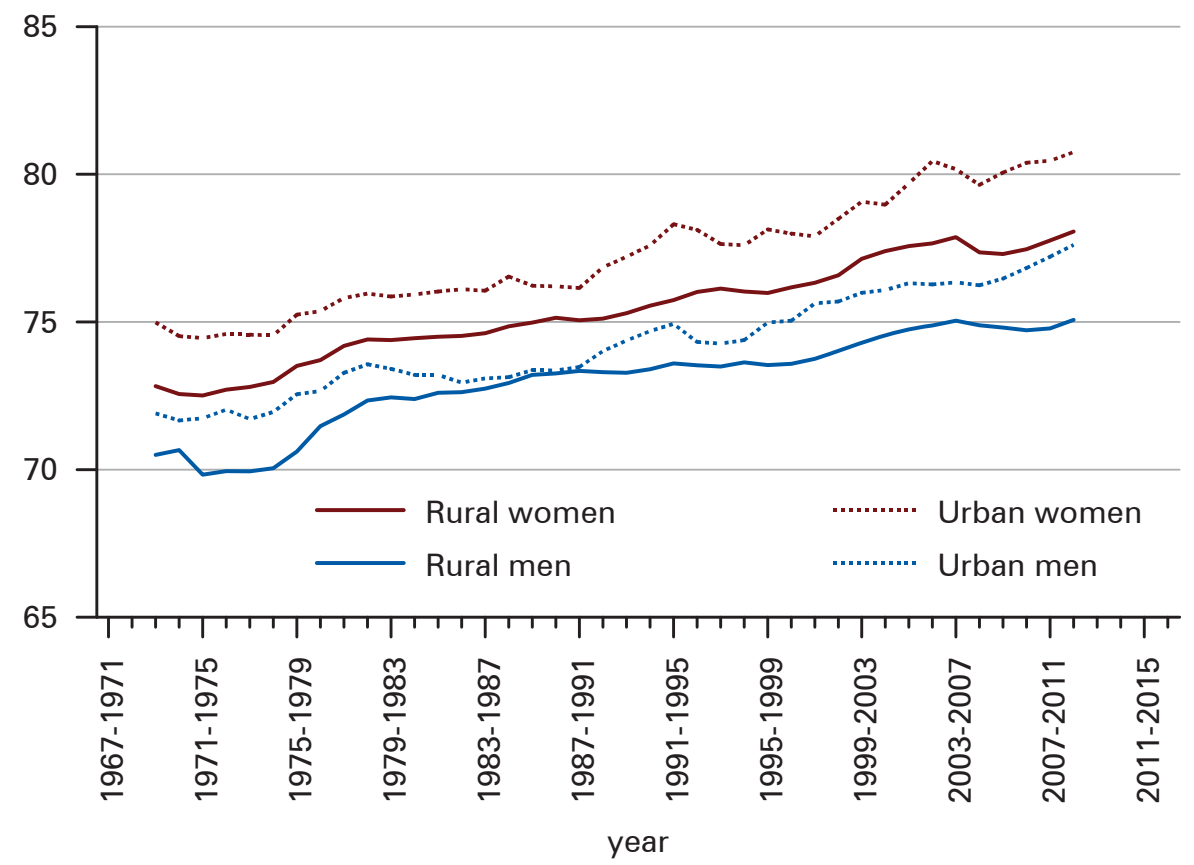

Source: Own calculations

women. Compared to the rural population, the urban population showed a consistent decline in C50 values during the transitional period, with narrower C50 values for urban women compared to urban men. Following a rapid decline in the 1980s, the C50 values stagnated during the 1990s. Women and men living in rural areas had similar C50 values, with a plateau apparent until the late 1990s. Nevertheless, by the early 2000s, rural women had narrower C50 values compared to their male counterparts. Also, urban men showed a modest decline in $\mathrm{C} 50$ values, exhibiting a plateau in the 1990s and 2000s. The trends and gender differentials of C50 in rural and urban populations have been the same since the mid-1980s: rural and urban women showed narrower C50 values than rural and urban men. The advantageous pace for rural and urban women in the later years of the transitional period resulted in a wider gap in $\mathrm{C} 50$ values between women and men in the rural and urban areas, similar to the pattern seen in developed nations (Kannisto 2000: Table 2).

Third, the trends in C50 indicated a coherent decline, leading to a convergence among the population categories. The convergence in $\mathrm{C} 50$ was faster among women compared to men. A stronger convergence in $\mathrm{C} 50$ among population categories manifest a greater concentration of deaths about $\mathrm{M}^{*}$ and hence, greater homogeneity in mortality, although India lags significantly behind developed nations in mortality transition. Thatcher et al. (2010: Table 3) demonstrate a rapid reduction in vari- 
Fig. 5: Distribution of age at death for intercensal periods for India, 1971-2013, by sex and residence

(a) Rural women

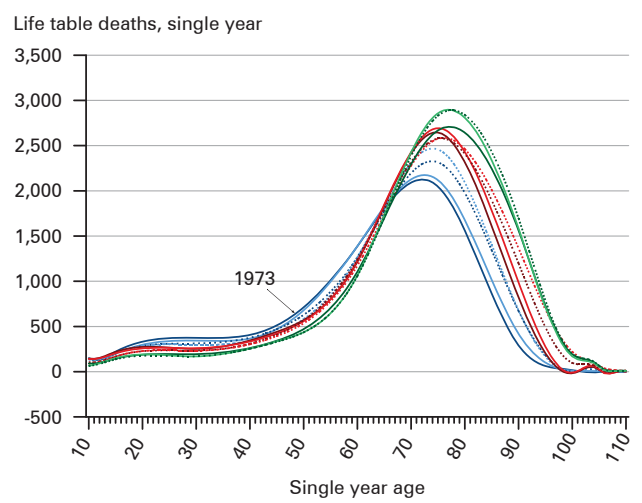

(b) Urban women

Life table deaths, single year

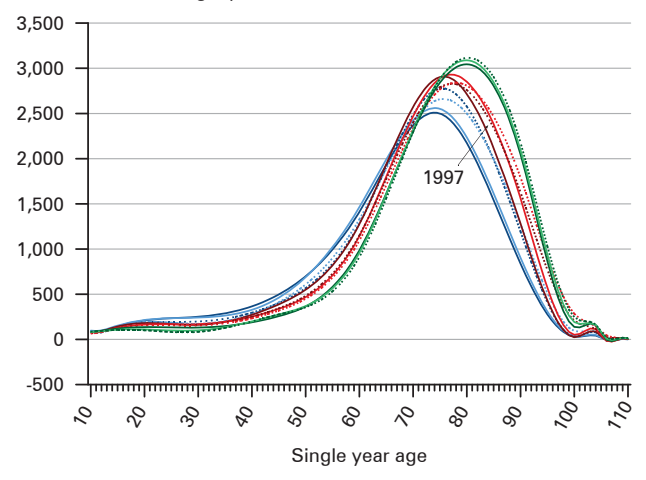

1971-1975

- 1975-1979

………... 1979-1083

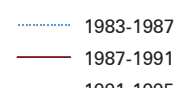

1987-1991

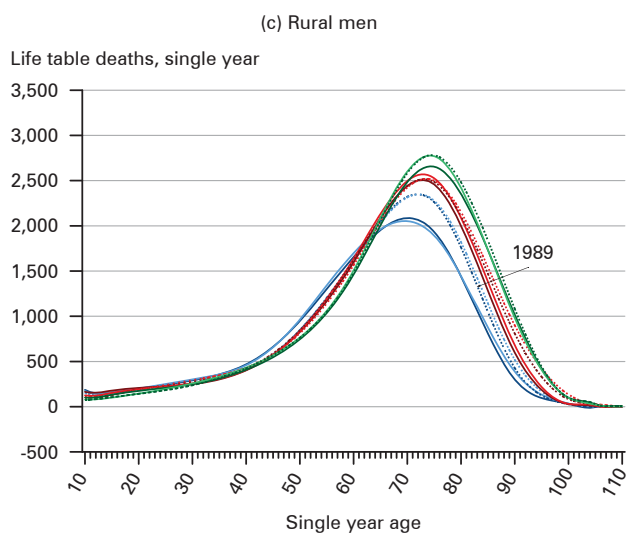

(d) Urban men

Life table deaths, single year

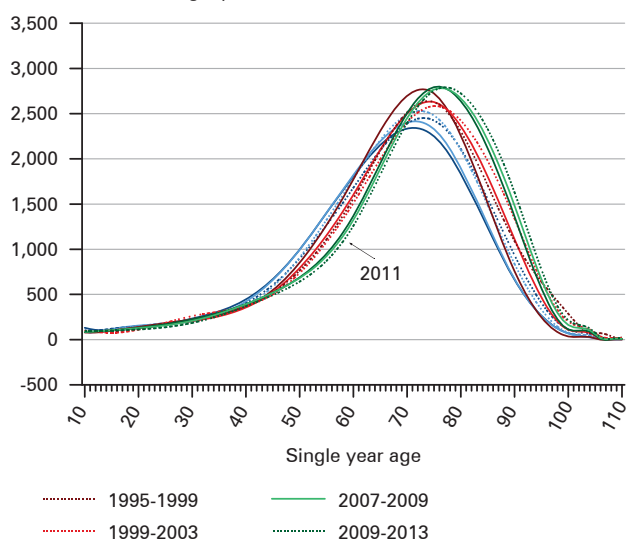

Note: The years 1973, 1989, 1997 and 2011 in the above graph represent the periods 19711975, 1987-1991, 1995-1999, and 2009-2013, respectively.

Source: Own calculations

ability in age at death and increase in $\mathrm{M}^{*}$ for Sweden, Switzerland, England \& Wales, France, and Italy in the period from 1900-1904 to 2000-2004, attesting to stronger mortality compression. The convergence in $\mathrm{M}^{*}$ is evident by sex in developed nations (Horiuchi et al. 2013: 45, Fig. 3; Missov et al. 2015: 1042, Fig. 4). Therefore, a stronger convergence in $\mathrm{C} 50$ among women indicates greater homogeneity in mortality than among their male counterparts.

Overall, the results of mortality compression measures confirm that the process of mortality compression has been developing at the national level since the 1990s. The two decades between 1970 and 1990 showed a modest progression in mortality compression while the latter two decades, from 1990 to 2013, marked a 
Fig. 6: $\quad$ Trends in C50 for India, 1970-2013, by population category

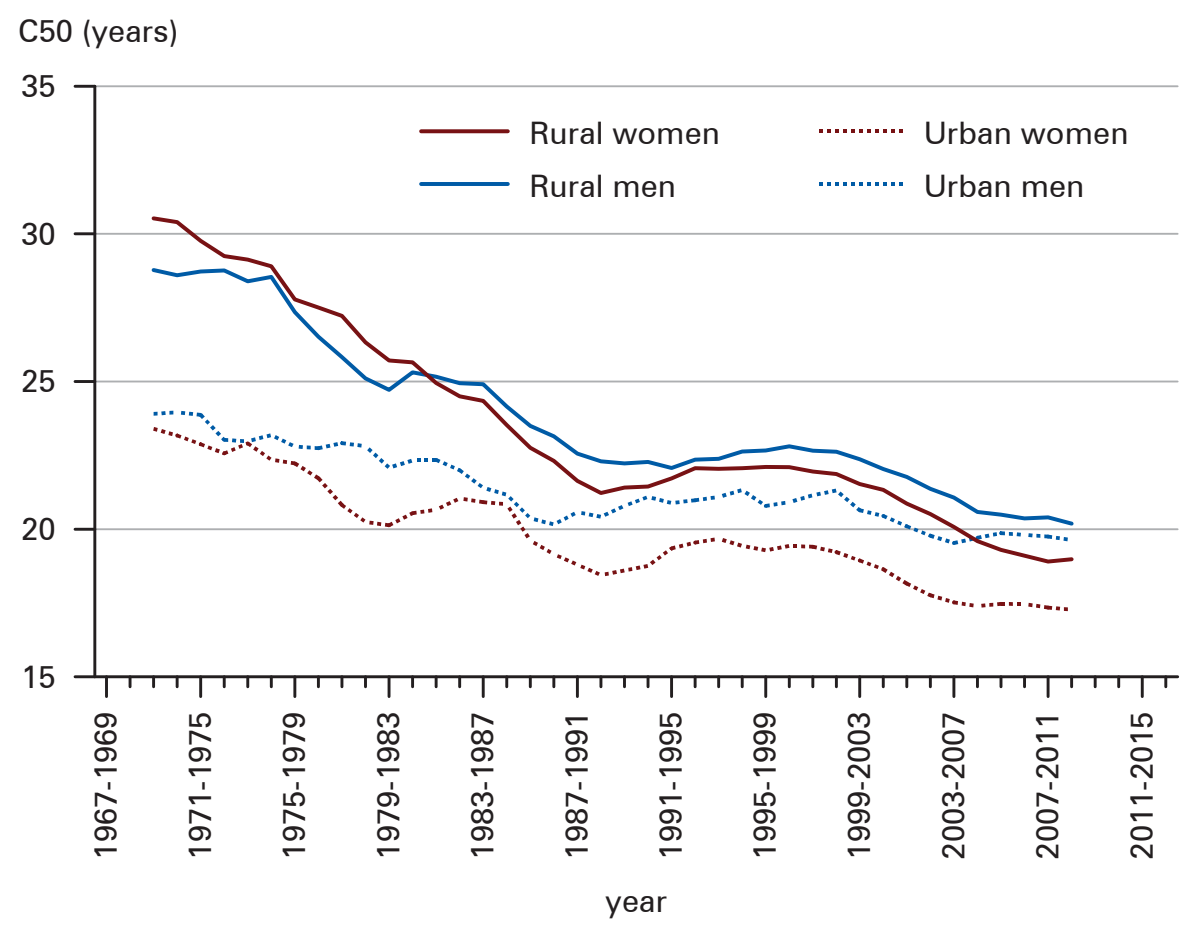

Source: Own calculations

stronger progression in mortality compression. Among the population categories, urban women experienced the strongest mortality compression during the transitional period.

\subsection{Variability in age at death}

Figure 7 displays the trends in $\mathrm{SD}(10+), \operatorname{SD}\left(\mathrm{M}^{*}+\right)$, and $\operatorname{SD}\left(<\mathrm{M}^{*}\right)$ along with the trends in C50 at the national level by population category between 1970 and 2013. A significant change in variance indicator points to the fact that a mortality decline developed in many age groups, contributing to the reduction in the variance of age at death. The almost static $\mathrm{SD}\left(\mathrm{M}^{*}+\right.$ ) values (Fig. 7) prove that changes in old-age mortality made a small contribution to the reduction in the variance of age at death in India. Developed nations have shown a consistent decline in $\mathrm{SD}\left(\mathrm{M}^{*}+\right)$ with a shift in $\mathrm{M}^{*}$, based on period life tables from Human Mortality Database (HMD) (Kannisto 2001: 164, Table 1; Thatcher et al. 2010), despite the fact that compression of deaths above $\mathrm{M}^{*}$ is a feature of period life tables and not cohort life tables (Ediev 2011). However, India has exhibited a feature of rapid decline in $\operatorname{SD}\left(<\mathrm{M}^{*}\right)$ with a shift in $M^{*}$. The $S D\left(<M^{*}\right)$ values for rural women declined from 27.4 years in the period 1970-1974 to 20.7 years in the period 2009-2013 (Fig. 7a). In contrast, the SD $\left(<\mathrm{M}^{*}\right.$ ) 
Fig. 7: Trends in $\mathrm{C50}, \mathrm{SD}(10+), \mathrm{SD}\left(\mathrm{M}^{*}+\right)$, and $\mathrm{SD}\left(<\mathrm{M}^{*}\right)$ for India, 1970-2013, by population category

(a) Rural women

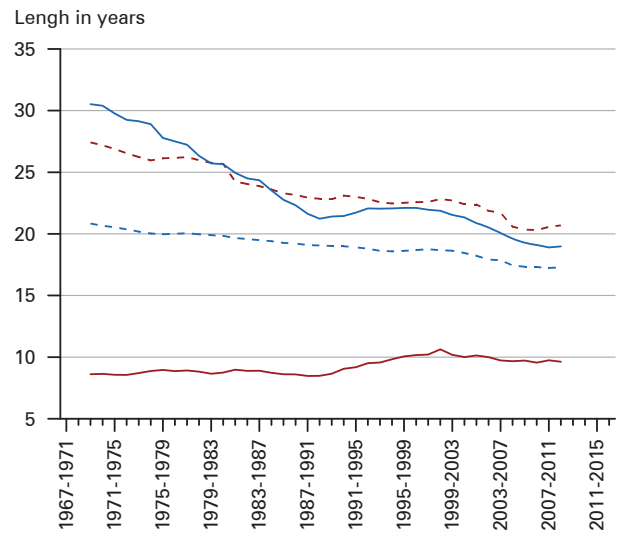

year

(b) Urban Women

Lengh in years

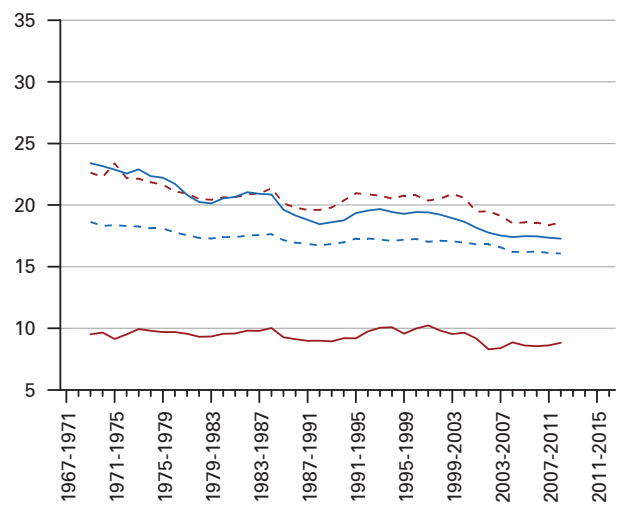

year

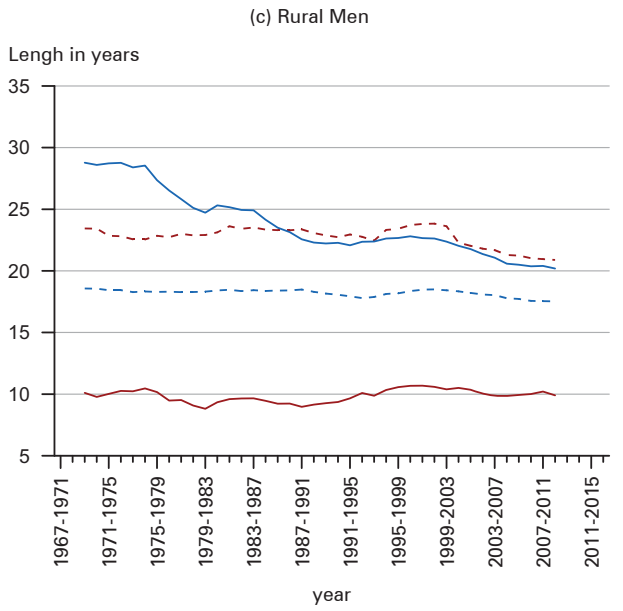

(d) Urban Men

Lengh in years

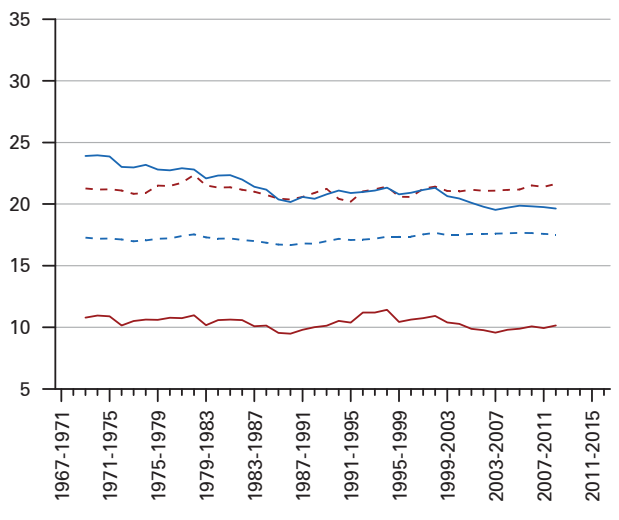

year

Source: Own calculations. Equations 2 to 4 were used for SDs

for rural men declined marginally by only 2.6 points to 20.8 years during the same period (Fig. 7c). For women, the trends in $\mathrm{SD}(10+)$ gradated down swiftly, which is consistent with the trends in $\mathrm{SD}\left(<\mathrm{M}^{*}\right)$. Of all $\mathrm{SDs}, \mathrm{SD}\left(<\mathrm{M}^{*}\right)$ better manifested the premature mortality, and hence the declining trends in $\operatorname{SD}\left(<\mathrm{M}^{*}\right)$ attested to the reduction in premature mortality. The trends in $\mathrm{SD}\left(<\mathrm{M}^{*}\right)$ were also consistent with the trends in $\mathrm{C50}$. This, therefore, demonstrates the dominant role of adult-age mortality compared to old-age mortality when it comes to a reduction in the variance of age at death. 
Fig. 8: Trends in the Gini coefficient at age $10\left(\mathrm{G}_{10}\right)$ for India, 1970-2013, by population category

Gini Coefficient at age 10

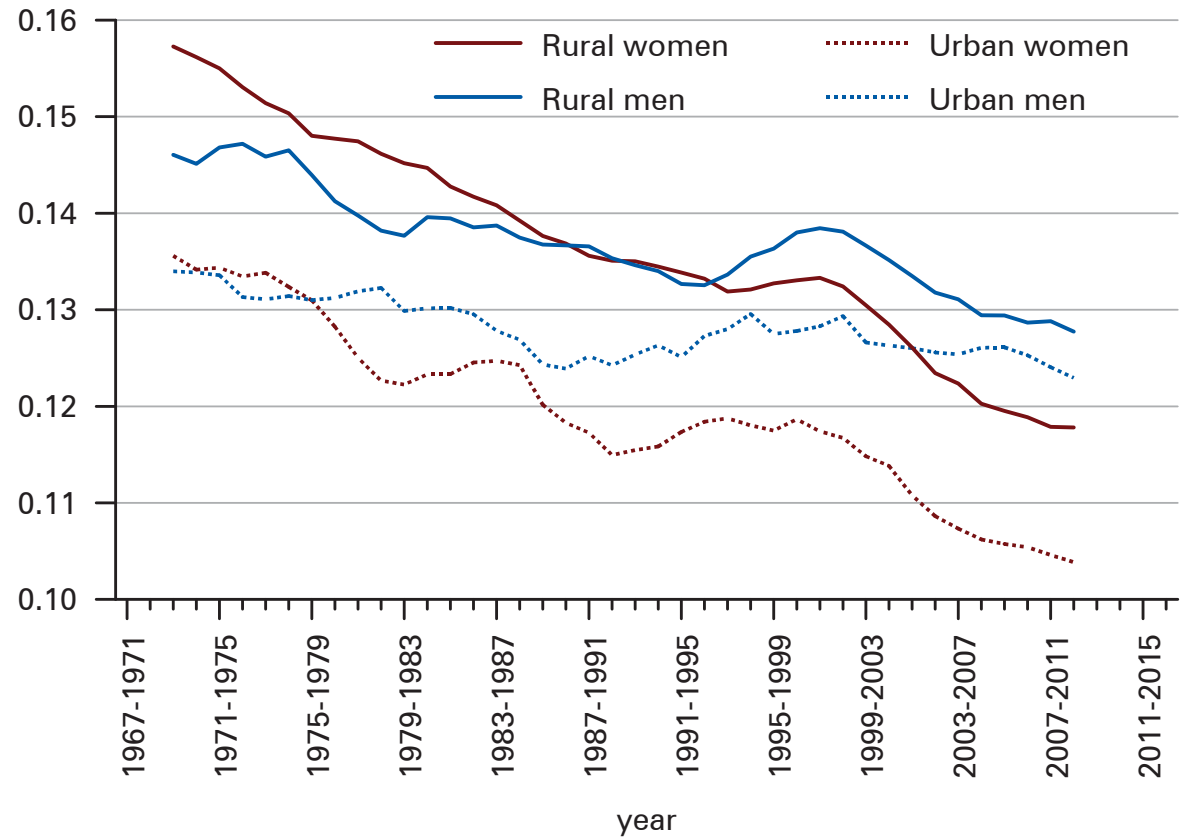

Source: Own calculations using Equation (5)

Another key measure is the Gini coefficient, which is used to comprehend variability in age at death (Edwards 2011; Hambleton et al. 2015). Figure 8 displays the trends in the Gini coefficient at age $10\left(\mathrm{G}_{10}\right)$ for women and men as well as rural and urban areas in India. A faster decline in $\mathrm{G}_{10}$ for women affirmed the rapid progression of homogeneity in mortality among women, which was intensive during the transitional period. Sorted by population category, urban women have had the lowest $\mathrm{G}_{10}$ since the late 1970s. Urban women achieved a low inequality value of 0.10 in the period 2009-2013 compared to a higher value of 0.14 in the early 1970 s. Compared to urban women, rural women showed near-stagnancy in the late 1990s, followed by a rapid decline in $\mathrm{G}_{10}$ since the early 2000s. Overall, women exhibited a swift reduction in $\mathrm{G}_{10}$. However, men showed a gradient increase in $\mathrm{G}_{10}$ in the latter half of the 1990s. This juxtaposition in men was attributable to modest, insufficient adult mortality decline. Hence, this rise in $\mathrm{G}_{10}$ among men led to a widening gap in the $\mathrm{G}_{10}$ between women and men in the later years of the transitional period. Németh (2017: 3, Fig. 1) and Shkolnikov et al. (2003: 342, Fig. 7) demonstrate a negative relationship between $\mathrm{G}_{0}$ and $\mathrm{e}_{0}$ and between $\mathrm{G}_{15}$ and $\mathrm{e}_{15}$. It may be noted that the reduction in variability in age at death is concomitant with the increase in the length of life (Smits/Monden 2009: 1119, Fig. 2). This relationship asserts that 
Fig. 9: The age-specific contribution to the Gini at age $10\left(\mathrm{G}_{10}\right)$ for India, 19702013, by population category

(a) Rural women

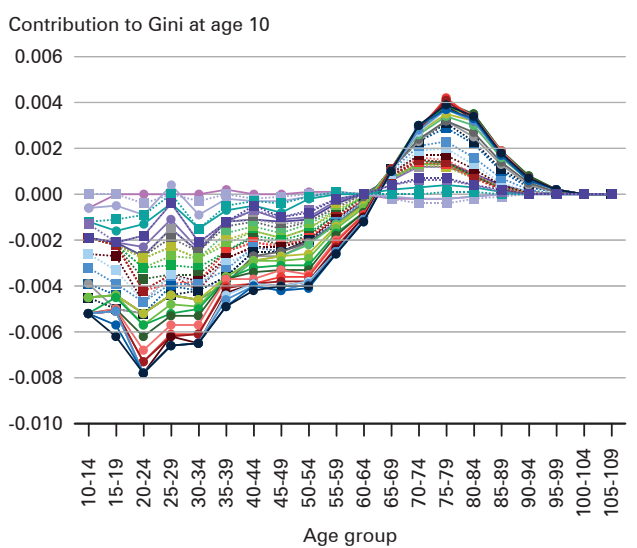

(b) Urban women

Contribution to Gini at age 10

0.006

0.004

0.002

0.000

$-0.00$

$-0.004$

$-0.006$

$-0.008$

$-0.010$

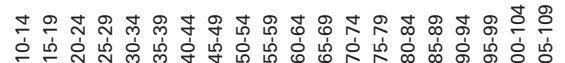

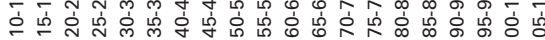

Age group (c) Rural men

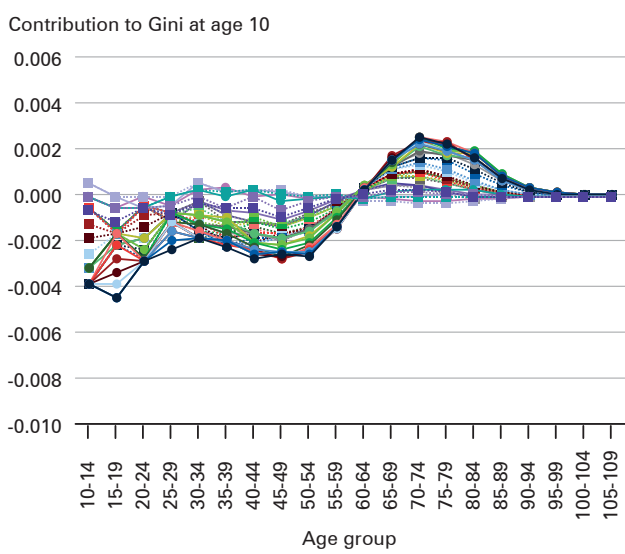

(d) Urban men

Contribution to Gini at age 10

0.006

0.004

0.002

0.000

$-0.002$

$-0.004$

$-0.006$

$-0.008$

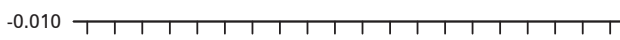

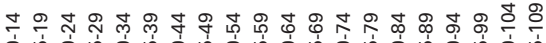

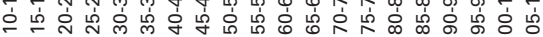

Age group

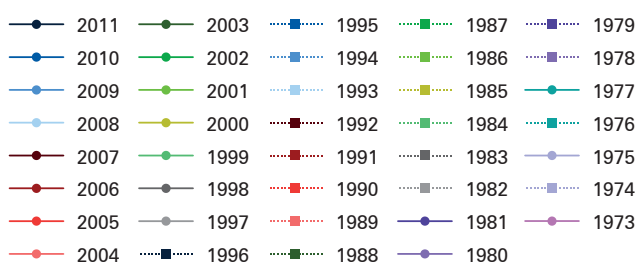

Note: The Gini coefficient was computed from abridged life tables for age 10 and above Source: Own calculations using Equation (6)

the gender differentials in $e_{0}$ contribute to the gender differentials in variability in age at death and vice versa. 
Figure 9 depicts a strong equalizing effect in the 10-59 age group and a passive dis-equalizing effect in old age groups (60 and above) to $\mathrm{G}_{10}$ during the entire examination period from 1970 to 2013. A similar equalizing effect of age groups below 65 years and a dis-equalizing effect of age groups above 65 years is apparent for women in the USA between 1900 and 1995 (Shkolnikov et al. 2003: 327, Table 7). In the 1970s and 1980s, the contribution of adult age groups (15-59 years) to $\mathrm{G}_{10}$ of rural women in India was prominent from the age group 15-29 years followed by the age group 30-44 years. By the early 1990s, the age group 15-29 years became the largest contributor to $\mathrm{G}_{10}$ of rural women. The female age group of 15-29 years taken together with the age group of 30-44 years (Fig. 9a) were the main contributors to the decline in $\mathrm{G}_{10}$ of rural women. Urban women showed a more interesting pattern of the adult age groups' contributions to $\mathrm{G}_{10}$. The adult age groups of 15-29 years, $30-44$ years, and $45-59$ years have contributed almost equally to $\mathrm{G}_{10}$ of urban women since the late 1970s (Fig. 9b). Altogether, the progressive contribution of the young adult age group (15-44 years) to $\mathrm{G}_{10}$ provides evidence of the progress towards homogeneity in mortality among women. On the other hand, rural and urban men aged 30-44 years made a significant contribution to the homogeneity in mortality (Fig. 9c and 9d). The contribution of young adult age group to $\mathrm{G}_{10}$ of men was nearly half that of women during the transitional period of 1970-2013. This small contribution in adult men was caused by high mortality at adult ages attributable to injuries and chronic NCDs.

The patterns of causes of death reveal that men compared to women had substantially higher toll of deaths attributable to injuries rather than to CDs and NCDs. A high concentration of deaths attributable to injuries of 25.5 percent and 12.8 percent was in the 30-44 and 45-54 age groups, respectively, among men in the period 2010-13, which was approximately two-fold as compared to women (ORG \& CC 2015: Statement 1.3B and $1.3 \mathrm{C}$ ). The $15-29$ age group had a similar concentration of deaths of approximately 27.5 percent of total deaths attributable to injuries for both men and women. The unintentional injuries (accidents) and intentional injuries (suicides) were responsible for 9.2 percent and 3.1 percent, respectively, of total deaths in men whereas 5.7 percent and 2.7 percent, respectively, of total deaths in women in the period 2010-13. The toll of deaths, 47 percent of total deaths attributable to accidents and 69 percent of total deaths attributable to suicides, were concentrated in the 15-44 age group among men. However, the corresponding figures for women aged 15-44 years were 26 percent of total deaths attributable to accidents and 78 percent of total deaths attributable to suicides. Additionally, men showed higher toll of deaths attributable to chronic NCDs in the 30-44 and 45-54 age groups as compared to women (ORG \& CC 2015).

Overall, the contribution by age groups revealed that adult-age mortality played a significant role in accelerating the pace of $\mathrm{G}_{10}$. Compared to women, men showed a modest progress towards homogeneity in mortality in the transitional period. Globally, the modest progression in $\mathrm{e}^{\dagger}$ for men compared to women is evident even in the most demographically developed countries such as Japan, France, Switzerland, England \& Wales, Germany, and Finland (Vaupel et al. 2011: 2, Table 1). CanudasRomo et al. (2016: 9, Fig. 1) and Singh/Ladusingh (2016: 46, Fig. 6; 47, Fig. 7) showed 
that younger, older adult and younger old age groups (30-74 years) made a major contribution to the gender gap in $\mathrm{e}_{0}$ and $\mathrm{e}^{\dagger}$ between the early 1970s and late 2000s, in India and its major states.

\subsection{Dominance of adult mortality in mortality compression in India}

Figure 10 and Figure 11 show the scatter plot between $\mathrm{C} 50$ and $\mathrm{SD}\left(<\mathrm{M}^{*}\right)$ and the scatter plot between $\mathrm{C}_{50}$ and $\mathrm{G}_{10}$, respectively, for the selected Indian states and population categories. Figure 10 reveals a close positive correlation between C50 and $S D\left(<M^{*}\right)$ for women rather than men. The average correlation coefficient, i.e. the mean value of correlation coefficients of the selected states excluding India, between $\mathrm{C} 50$ and $\mathrm{SD}\left(<\mathrm{M}^{*}\right)$ for rural and urban women was 0.85 and 0.86 , respectively. For the selected states, a correlation coefficient of more than 0.80 was found for women, with the exception of women in Assam and Haryana. On the other hand, the average correlation coefficient for rural and urban men was 0.50 and 0.30 , respectively. For these states, there was considerable variation in the correlation coefficient between $\mathrm{C} 50$ and $\mathrm{SD}\left(<\mathrm{M}^{*}+\right)$ between women and men, given the reduction in premature mortality. Figure 11 shows a close positive correlation between C50

Fig. 10: Scatter plot of $C 50$ against $S D\left(<\mathrm{M}^{*}\right)$ for India and its twelve biggest states, $1970-2013$, by population category

(a) Rural women

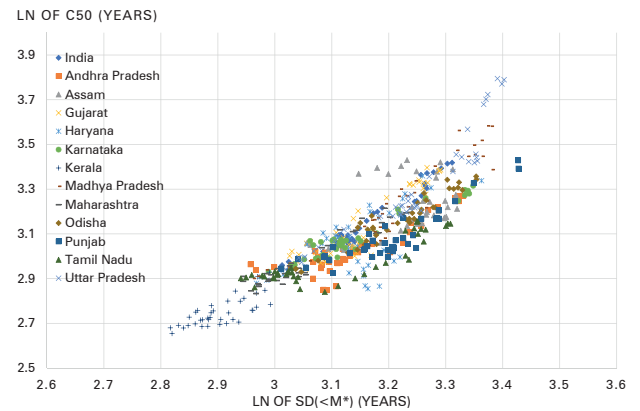

(b) Urban women

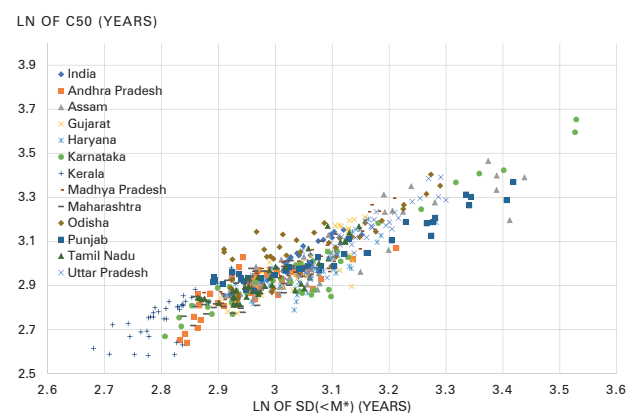

(c) Rural men

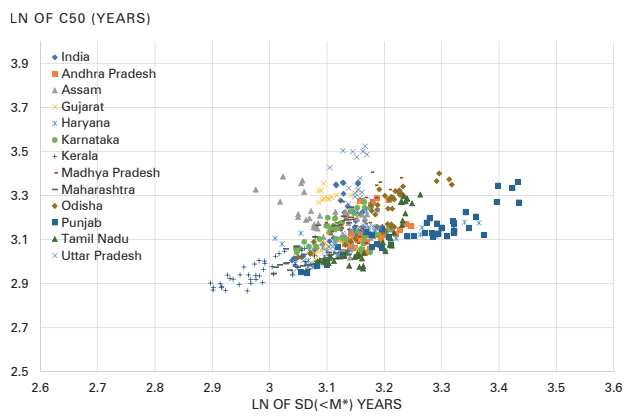

(d) Urban men

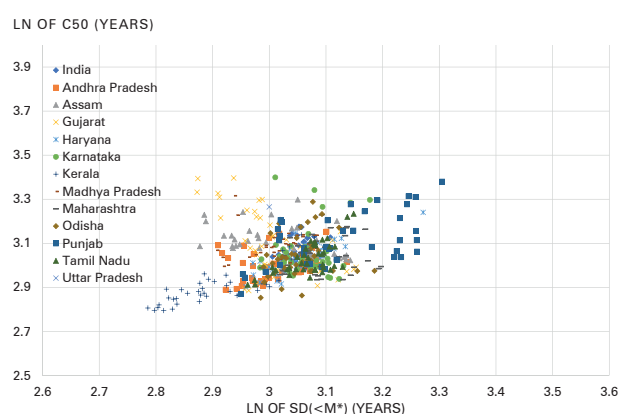

Source: Own calculations 
Fig. 11: Scatter plot of C50 against the Gini coefficient at age $10\left(\mathrm{G}_{10}\right)$ for India and its twelve biggest states, 1970-2013, by population category

(a) Rural women

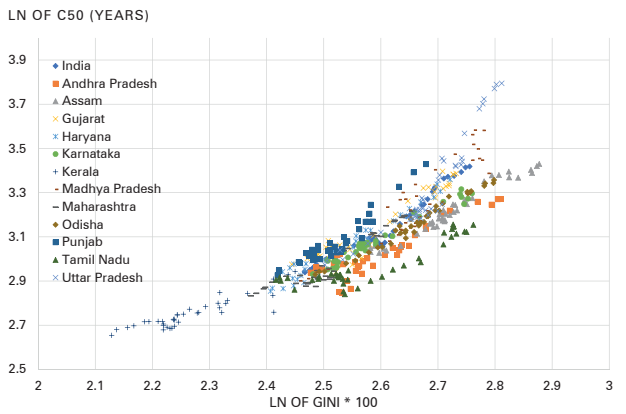

(b) Urban women

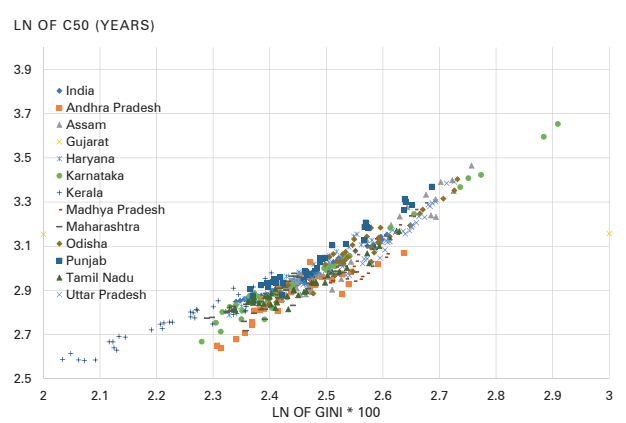

(c) Rural men

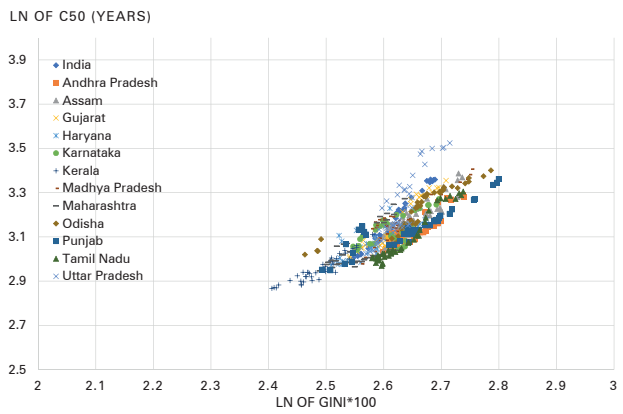

(d) Urban men

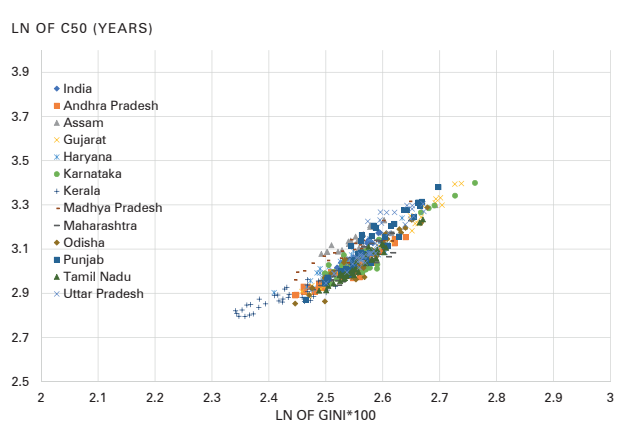

Source: Own calculations

and $\mathrm{G}_{10}$ for the population categories. The average correlation coefficient between $\mathrm{C} 50$ and $\mathrm{G}_{10}$ for women and men amounted to 0.94 and 0.88 , respectively. It is noteworthy that $\mathrm{G}_{10}$ in comparison to $\mathrm{SD}\left(<\mathrm{M}^{*}\right)$ revealed a higher correlation coefficient for men. This high correlation can be explained by a similar contribution of oldage mortality to $\mathrm{G}_{10}$ (Fig. 9) for both sexes but with a slight advantage for women (Chaurasia 2010). The results indicate greater consistency between the impressive progression in mortality compression and the reduction in premature mortality of the respective states.

The selected twelve states have shown variation in the pace of mortality compression despite the progress in mortality compression caused by the same factor: the reduction in premature mortality. In urban areas, states such as Andhra Pradesh, Gujarat, Kerala, Maharashtra, Punjab, and Tamil Nadu displayed narrower C50 values for women than for men from the early 1970s. Only two states, Odisha and Uttar Pradesh, had wider C50 values for urban women than for urban men until the late 1990s. On the other hand, in rural areas, Uttar Pradesh, Madhya Pradesh, and Assam showed wider C50 values for women than men for a large portion of the transitional period from 1970 to 2013. Rural women in the states of Madhya Pradesh and Assam outpaced rural men in the progression of mortality compression by the 
late 1990s. The states of Andhra Pradesh, Kerala, Maharashtra, Odisha, and Tamil Nadu showed narrower C50 values for rural women than for rural men from the beginning of the transitional period. Altogether, the demographically pioneer states compared to backward states showed stronger mortality compression for women than men. Hence, these states make a major contribution to the progression in mortality compression for India as a whole.

In sum, adult mortality decline plays a determining role in the regional variation in mortality compression. Additionally, results show that C50 is a more appropriate measure to assess mortality compression for a developing country like India because it is sensitive to adult-age mortality as well as old-age mortality. Kannisto (2000) has shown the application of the $\mathrm{C} 50$ method for the developed nations passing through the low mortality regime.

\subsection{Convergence in mortality compression}

Figure 12 depicts a convergence in $\mathrm{C50}$ among the selected Indian states for all the population categories in the transitional period from 1970 to 2013. The interquartile range (IQR) of C50 for rural and urban women across the twelve states, excluding India as a whole, narrowed from 6.0 years and 5.1 years, respectively, in the period $1971-1975^{1}$ to 1.4 years and 1.1 years, respectively, in the period 2009-2013. However, beta and sigma convergence are better measures in comparison to IQR. Figure 13 provides a summary of convergence in $\mathrm{C} 50$ for all population categories in the transitional period, using beta convergence method (Barro/Sala i Martin 1990; Janssen et al. 2016). It shows absolute beta convergence in C50. Rural and urban women showed strong linearity with high adjusted $R^{2}$ values of 94 percent and 92 percent, respectively. High linearity among women indicates a similar pace of decline in C50 for the selected states. Compared to women, rural men and urban men showed a lower adjusted $R^{2}$ but had larger and statistically significant beta coefficient values, indicating faster convergence (Fig. 13: $c$ and d). These results revealed that beta convergence in $\mathrm{C} 50$ among women was consistent and at a stronger level of mortality compression, whereas beta convergence in $\mathrm{C} 50$ among men was faster but at a moderate level of mortality compression.

Figure 14 shows the trends in $r_{s}(t)$ for India and the twelve selected Indian states for all population categories in the transitional period. Urban women followed by rural women showed a coherent decline in $r_{s}(t)$ in the later years of the transitional period, whereas rural and urban men showed stagnancy over time. It is noteworthy that the demographically most advanced state of Kerala had the lowest values of C50, comparable to those of developed nations, throughout the transitional period. The state of Kerala, passing through the last stage of the demographic transition, showed $\mathrm{C} 50\left(\mathrm{SD}\left(\mathrm{M}^{*}+\right)\right)$ values similar to those of developed nations. Table 5 provides a comparison of $\mathrm{C} 50\left(\mathrm{SD}\left(\mathrm{M}^{*}+\right)\right)$ values for Indian women and women from

1 SRS provides ASDR of the Indian states Kerala, Karnataka, and Tamil Nadu from the year 1971 onwards. For these Indian states, the initial period is 1971-1975. 
Fig. 12: Trends in C50 for India and its twelve biggest states, 1970-2013, by population category

(a) Rural women

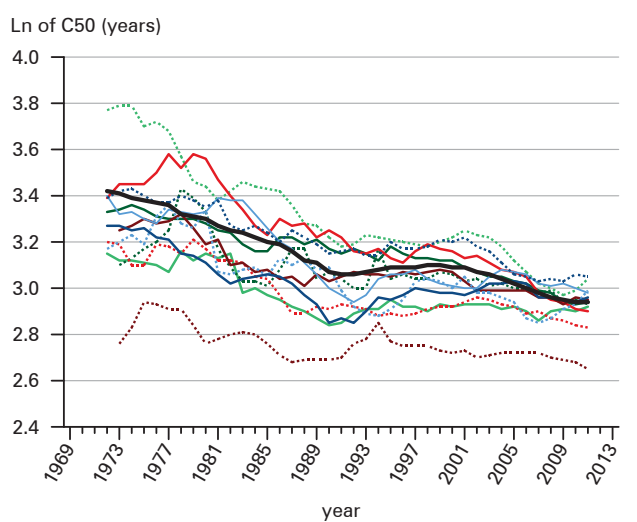

(b) Urban women

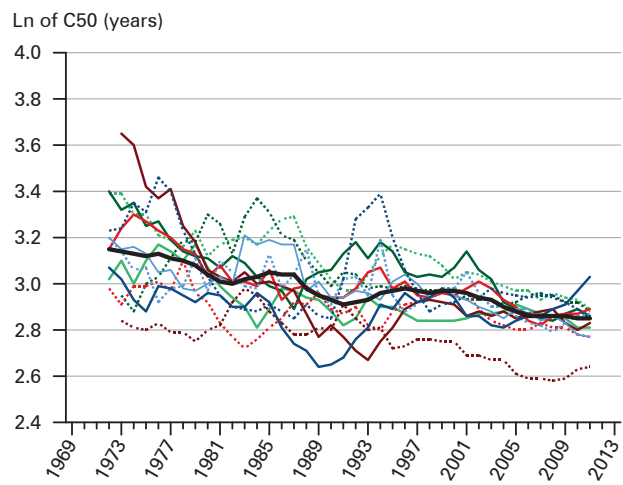

year

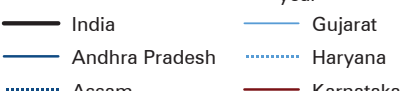

............ Assam (c) Rural men

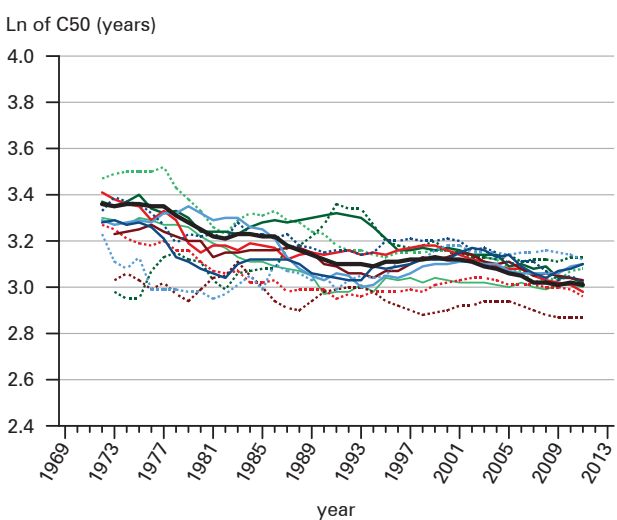

(d) Urban men

Ln of C50 (years)

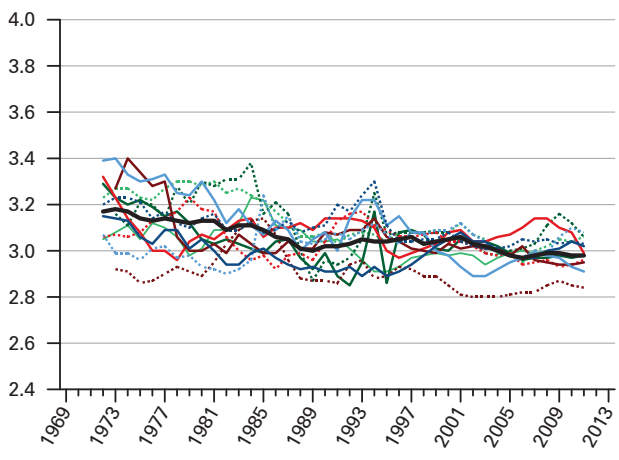

year

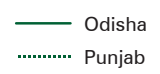

..........- Uttar Pradesh

- Madhya Pradesh ……... Punjab

Maharashtra Tamil Nadu

Source: Own calculations

the state of Kerala and women in developed nations such as Switzerland, England, the Netherlands, and Finland. Kannisto (2000: Table 1) demonstrated C50 (SD( $\left.\left.\mathrm{M}^{*}+\right)\right)$ values and the change in $\mathrm{C50}\left(\mathrm{SD}\left(\mathrm{M}^{*}+\right)\right)$ values of women over time for the same developed countries of Switzerland, England, the Netherlands, and Finland. The C50 $\left(\mathrm{SD}\left(\mathrm{M}^{*}+\right)\right)$ value of women from Kerala was $14.2(6.5)$ years in the period 2009-2013, which is close to the C50 value of England at 14.8 (7.0) years in the period 1990-1992 as well as to that of the Netherlands at 14.4 (6.5) years in the period 1990-1995. This is despite the fact that for Kerala the $r_{s}(t)$ values for rural women and urban women were nearly stagnant during the transitional period. Importantly, among women, Kerala was an outlier in the 1970s and 1980s, and Assam, Maharashtra, Punjab, and Haryana were outliers in the 1990s. Nevertheless, women from other states and 
Fig. 13: Scatter plots of C50 in 1971-1975 against the annual change in C50 over the period 1971-2013 and regression estimates for India and its twelve biggest states, by population category

(a) Rural women

Annual change in C50 during 1971-2013

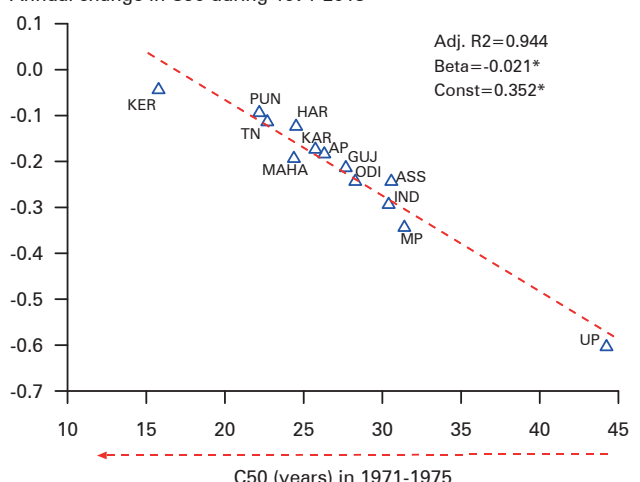

(b) Urban women

Annual change in C50 during 1971-2013

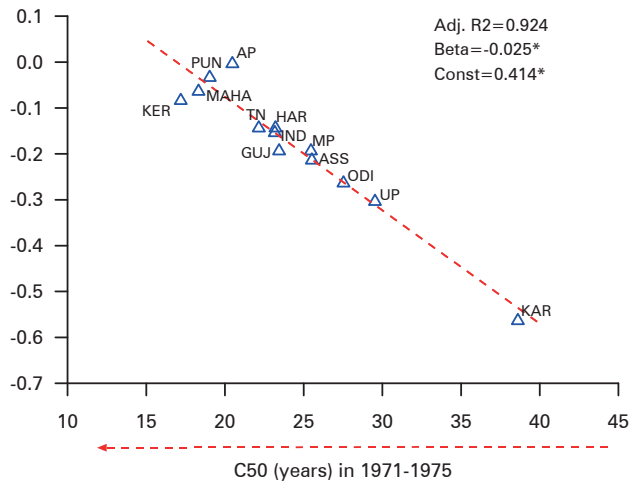

(c) Rural men

Annual change in C50 during 1971-2013

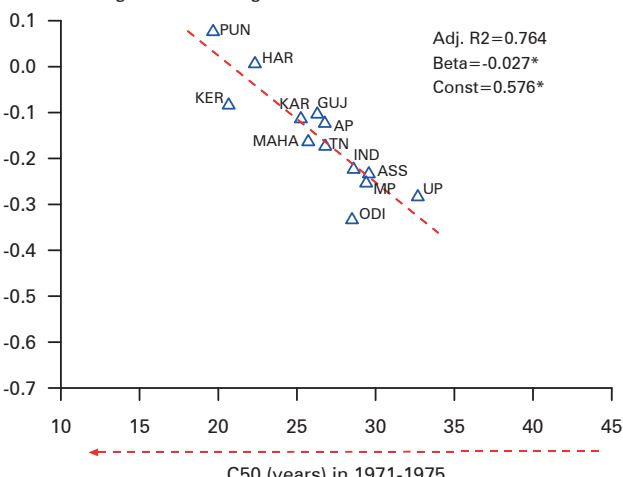

(d) Urban men

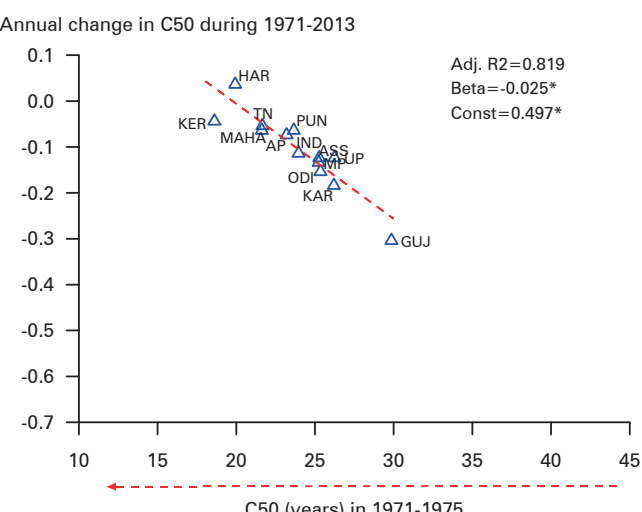

Note: * represents significance of 1 percent level

AP: Andhra Pradesh, ASS: Assam, GUJ: Gujarat, HAR: Haryana, IND: India, KAR: Karnataka, KER: Kerala, MAHA: Maharashtra, MP: Madhya Pradesh, ODI: Odisha, PUN: Punjab, TN: Tamil Nadu, UP: Uttar Pradesh

Source: Own calculations using Equation (7)

India as a whole showed $r_{s}(t)$ values tending towards $r_{s}(t)$ values of the women of Kerala since the early 2000s. Undoubtedly, sigma convergence together with strong beta convergence in the C50 for rural and urban women were evident from the progression in mortality compression and variability in age at death during the transitional period. However, it is important to note that the average $r_{s}(t)$, i.e. the mean value of $r_{s}(t)$ in the late 2000s of the selected states excluding India as a whole, was 1.16 and 1.18 for urban women and rural women, respectively, which is higher than the approaching value of 1.0. Sigma convergence was not evident for men; how- 
Fig. 14: Trends in ratio $r_{s}(t)\left(\mathrm{SD}\left(<\mathrm{M}^{*}\right) / \mathrm{SD}(10+)\right)$ for India and its twelve biggest states, 1970-2013, by population category

(a) Rural women

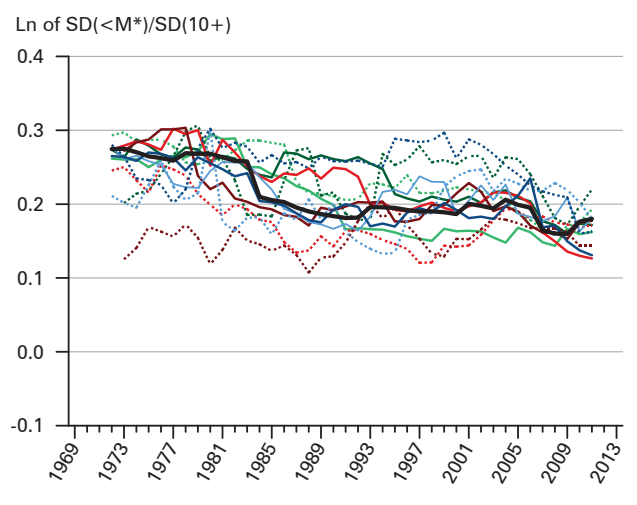

year

(b) Urban women

Ln of $\mathrm{SD}\left(<\mathrm{M}^{*}\right) / \mathrm{SD}(10+)$

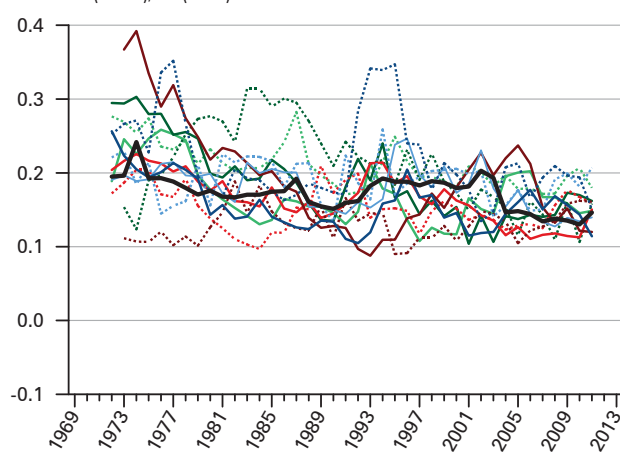

year

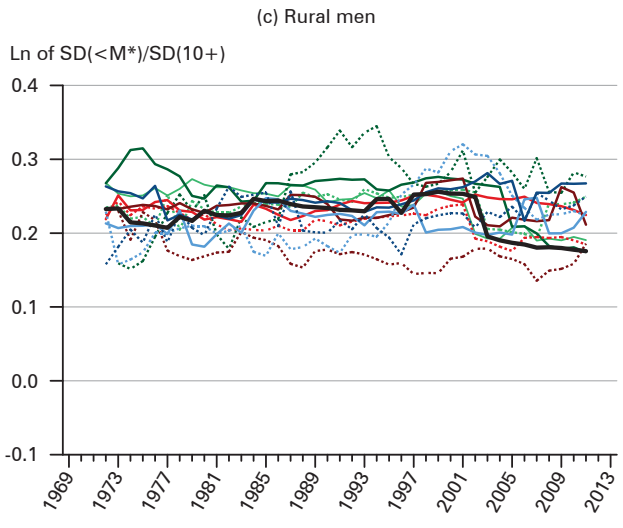

year

(d) Urban men

Ln of $\mathrm{SD}\left(<\mathrm{M}^{*}\right) / \mathrm{SD}(10+)$

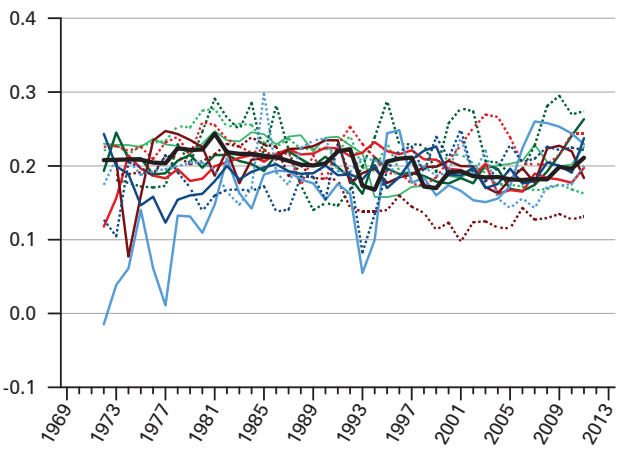

year

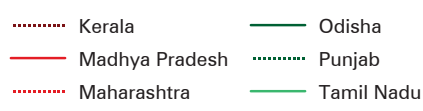

.... Uttar Pradesh

Karnata

........... Maharashtra

Tamil Nadu

Source: Own calculations using Equation (8)

ever, a beta convergence was evident. The state of Kerala remained an outlier in sigma convergence for men compared to other states, as is evident from the trends in $r_{s}(t)$ during the transitional period. Overall, the ratio $\left(r_{s}(t)\right)$ is a useful tool for testing sigma convergence for mortality compression.

\section{Discussion}

This study explored the progress of mortality transition during 44 years between 1970 and 2013 for India and its twelve biggest states using measures of mortality compression and variability in age at death. The progression in mortality compres- 
Tab. 5: $\quad \mathrm{C} 50\left(\mathrm{SD}\left(\mathrm{M}^{*}+\right)\right)$ for women of selected developed countries, India and Kerala (Indian state)

\begin{tabular}{lcccccc}
\hline Time Period & Switzerland & England & Netherlands & Finland & India & Kerala \\
\hline $1876-1880$ & $35.3(8.8)$ & & & & & \\
$1988-1993$ & $13.6(6.0)$ & & & & & \\
$1891-1900$ & & $31.7(8.9)$ & & & & \\
$1990-1992$ & & $14.8(7.0)$ & & & & \\
$1850-1860$ & & & $49.7(8.5)$ & & & \\
$1990-1995$ & & $14.4(6.5)$ & & $36.7(8.3)$ & & \\
$1881-1890$ & & & $12.5(6.5)$ & & $28.5(8.5)$ & $15.5(7.2)$ \\
$1991-1995$ & & & & $18.6(9.5)$ & $14.2(6.5)$ \\
$1971-1975$ & & & & & & \\
$2009-2013$ & & & & & & \\
\hline
\end{tabular}

Source: The figures for four developed countries are taken from Kannisto (2000: Table 1); Own calculations for India and state Kerala

sion spurred by variability in age at death in a high mortality regime versus in a medium or a low mortality regime was modulated by the contribution of adult-age mortality and old-age mortality. We estimated C50 (Kannisto 2000: see Annex) and the Gini coefficient at age $10\left(\mathrm{G}_{10}\right)$ (Shkolnikov et al. 2003) from the distribution of age at death and analysed contribution of many age groups for comprehending the progress in mortality compression and variability in age at death. We investigated convergence in mortality compression among different Indian states, using the beta and sigma convergence method (Barro/Sala i Martin 1990; Janssen et al. 2016).

The phenomenon of mortality compression is a fundamental demographic process. The developed countries have shown a remarkable contribution of old-age mortality to the progress of mortality compression (Cheung/Robine 2007; Ediev 2013; Kannisto 2001; Lynch/Brown 2001; Thatcher et al. 2010). For a developing country like India, a greater fall in IMR since the late 1980s (ORG 2020; RGI 19722013) reduced the dominance of childhood mortality to a more progressive phase of mortality transition wherein adult mortality (Rajaratnam et al. 2010: 1709) demonstrated a greater role in the progress of mortality compression and variability in age at death. For India and its twelve biggest states, the C50 values (Fig. 6) and the Gini coefficients (Fig. 8) declined from a high value to a low value in 1970-2013, whereas the reduction was greater for women than for men. The progression in mortality compression was modest in the 1970s and 1980s and has been swift since the mid-1990s. Urban women among the population categories showed the strongest mortality compression and the lowest variability in age at death.

The flattening of the age pattern of mortality (Fig. 1 and 2) (Bongaarts 2005; Horiuchi/Wilmoth 1998) and rise in modal age at death (Fig. 4) (Canudas-Romo 2008; Thatcher et al. 2010; Yadav/Arokiasamy 2014: Fig. 8) were conspicuous in the period 1970-2013. The rapid decline in infant and child mortality in the 1970s and 1980s (ORG 2020; RG/ 1972-2013) transformed the distribution of age at death from a bimodal distribution to a unimodal distribution (Arokiasamy/Yadav 2014: Fig. 3). This 
development proved the most advantageous when adult-age mortality was most dominant since the early 1990s by outlining the contours of mortality (Edwards/ Tuljapurkar 2005; Zhang/Vaupe/ 2009). The decline in both adult and infant mortality led to the sufficient reduction in the premature mortality (Fig. 3) (McKee/Shkolnikov 2001) which mainly contributed to the progression in mortality compression. The variance of age at death in adult age (Cheung/Robine 2007) rather than in old age reduced variability in age at death substantially (Fig. 7) (Engelman et al. 2010; Wilmoth/Horiuchi 1999). The decomposition analysis of the $\mathrm{G}_{10}$ (Shkolnikov et al. 2003) revealed that the 15-29 age group taken together with the 30-44 age group were the main contributors, more for women than men, to the decline in variability in age at death (Fig. 9). The decrease in adult heterogeneity has a positive relationship with the increase in adult longevity (Cheung et al. 2009), and hence the individuals who survived at old ages have been homogeneous enough to propel the progression in mortality compression, and eventually, they shaped this phase of mortality compression to a greater extent than ever before.

The low variability in age at death is strongly associated with the rise in life expectancy (Németh 2017: Fig. 1; Shkolnikov et al. 2003: Fig. 7). Women showed a strong mortality compression (Kannisto 2000) and a low variability in age at death (Hambleton et al. 2015) that was primarily the result of the aversion of maternal deaths in their reproductive ages (Fig. 9) (MoHFW 2014). A close negative correlation manifested between the reduction in premature mortality and measures of mortality compression (Fig. 10) and variability in age at death (Fig. 11), a bit stronger for women than men. Compared to women, men showed a weak mortality compression with modest progress of homogeneity in mortality which is evident even in the most developed countries such as Japan, France, Switzerland, England \& Wales, Germany, and Finland (Vaupel et al. 2011: 2, Table 1). Comparatively, gender differentials in mortality compression was strongly evident in India and its states. Nevertheless, women and men in the different regions (states) of India showed a consistent progression in mortality compression (Fig. 12). The pioneer Indian states (Table 4) with better mortality conditions showed stronger mortality compression as compared to backward states (Smits/Monden 2009; Subramanian et al. 2006). Despite this fact of regional variation and gender differentials in mortality compression, the progress in mortality compression both for pioneer and backward states was caused by the same factor: the reduction in premature mortality (Fig. 3).

The Indian states demonstrate (beta and sigma) convergence in C50 (Janssen et al. 2016). Women at a stronger level of mortality compression showed a consistent beta convergence in C50 (Fig. 13: a and b). However, men at moderate level of mortality compression showed a faster convergence in C50 (Fig. 13: c and d). Sigma convergence was evident for women but not for men among Indian states (Fig. 14). The results of sigma convergence revealed that Indian states tended to follow the state of Kerala which showed strong mortality compression similar to that of developed nations.

Studies based on HMD indicated that developed nations have advanced to the last stage of mortality transition with a stronger mortality compression and homogeneity in mortality (Cheung et al. 2009; Ediev 2011, 2013; Edwards/Tuljapurkar 
2005; Horiuchi et al. 2013; Kannisto 2000; Lynch/Brown 2001; Myers/Manton 1984; Nusselder/Mackenbach 1996; Thatcher et al. 2010; Wilmoth/Horiuchi 1999). Low variability in age at death is primarily explained by the reduction in premature adult mortality. Many countries achieved a high level of $e_{0}$ in a shorter time with lower variability in age at death than more demographically advanced countries (Seaman et al. 2016; Smits/Monden 2009). India and its state Kerala showed a faster progress in mortality compression when compared to developed nations (Table 5). These developments in mortality demonstrated that the reduction in premature mortality vis-à-vis lower variability in age at death is a prerequisite for a mortality compression.

The study demonstrated that the reduction in premature mortality has been the reinforcing factor for the progress in mortality compression and variability in age at death. Women in India as a whole and in the twelve biggest Indian states showed that a reduction in premature mortality attributable to the rapid decline in young adult mortality was concomitant of the decline in Maternal Mortality Ratio (MMR) (Arokiasamy 2004; Clark 1987; Coale 1991; Memoire 2007; RG/ 1972-2013: Table 13). However, several backward Indian states - namely, Uttar Pradesh, Odisha, Madhya Pradesh, and Assam - have had high MMR levels compared to the state of Haryana and the pioneer Indian states.

Gender differentials in mortality compression highlighted the variance in adult mortality as the primary deterrent for men in India. The weak mortality compression for men is explained by the high variability in age at death and the low $\mathrm{e}_{0}$ (Németh 2017; Shkolnikov et al. 2003). Men aged 15-29 years have shown a negligible contribution to variability in age at death in the transitional period. The pace of adult mortality decline was slower for men (Rajaratnam et al. 2010: 1709) arising from relatively higher adult mortality resulting from a greater risk of deaths due to accidents and suicides (Global Burden of Disease Collaborative Network 2018; ORG 1979; ORG 2015, 2019). Specific interventions for adult survival focusing on men in the 15-29 and 30-44 age groups is now crucial, which essentially requires controlling deaths from injuries, violence, cardiovascular diseases, and lifestyle diseases, at which developed nations have been successful (Balia/Jones 2008; McKee/ Shkolnikov 2001). The high adult mortality in men, which was disregarded, has now become a significant cause of the lag in mortality transition. It indicates that programmes that reduce under-five mortality have not had a greater impact on the survival of adult men who are exposed to death from external causes (Rajaratnam et al. 2010). Averting deaths in the 15-29 age group is of prime importance for both women and men. Rural women outpaced rural and urban men in mortality compression because of the remarkable contribution of the 15-29 age group to variability in age at death. It is also essential to ensure an equal contribution from many age groups in reproductive ages of rural women as this has reinforced urban women in achieving low variability in age at death and a strong mortality compression. 


\section{Conclusion}

This study reveals important insights on India's progress of mortality transition during 44 years between 1970 and 2013. Measures of mortality compression and variability in age at death are worthwhile and useful to assess the progress of mortality transition. The progress of mortality compression and variability in age at death forge a bridge between the transformation in age pattern of mortality and the process of mortality transition. The progress in mortality transition in India and its major states is accompanied by notable progression in mortality compression and a sizeable reduction in variability in age at death during the transitional period. The process of mortality compression and the multiplying homogeneity in mortality have been stronger since the mid-1990s, with a notable improvement in young adult mortality $\left({ }_{30} q_{15}\right)$. Mortality transition changed in this phase due to strong mortality compression and multiplying homogeneity, and therefore, the decade of the 2000 s marked a distinct phase of mortality transition for India. Indeed, in contrast to developed nations, India and its major states have made a significant contribution to mortality compression from adult-age mortality rather than old-age mortality and have seen progress in mortality compression in a shorter span of time. Overall, this study reveals that mortality transition in India has entered an early phase of a low mortality regime. The convergence in the Indian states, in accordance with their relative level of $e_{0}$, shows that the rapid progression in mortality compression is caused by the reduction in premature mortality, more intensively for women than men. Men show a lag in mortality transition primarily because of the insufficient reduction in premature mortality and weak morality compression. This lag in mortality transition represents a major concern for adult men. India and its states need an inclusive health policy focusing on adult men, which would extend life expectancy and would lower variability in age at death.

\section{Acknowledgements}

The authors are thankful to Prof. Eileen Crimmins (PhD), University Professor, AARP Chair in Gerontology, USC Leonard Davis School of Gerontology, and Director, Multidisciplinary Research Training in Gerontology PhD Program for her critical suggestions and comments on this paper. The authors are also thankful to the International Union for the Scientific Study of Population (IUSSP) 2017, Population Association of America (PAA) 2018, 2020, Asian Population Association (APA) 2017, 2018 for giving opportunities for presenting the paper in the poster sessions. Authors are grateful to the anonymous reviewers for their comments and suggestions.

\section{References}

Aburto, José Manuel; van Raalte, Alyson 2018: Lifespan Dispersion in Times of Life Expectancy Fluctuation: The Case of Central and Eastern Europe. In: Demography 55,6: 2071-2096. https://doi.org/10.1007/s13524-018-0729-9 
Arokiasamy, Perianayagam 2004: Regional Patterns of Sex Bias and Excess Female Child Mortality. In: Population (English Edition, 2002) 59,6: 831-863.

Arokiasamy, Perianayagam; Yadav, Suryakant 2014: Changing Age Patterns of Morbidity Vis-à-vis Mortality in India. In: Journal of Biosocial Science 46,4: 462-479. https://doi. org/10.1017/S002193201300062X

Balia, Silvia; Jones, Andrew M. 2008: Mortality, lifestyle and socio-economic status. In: Journal of health economics 27,1: 1-26. https://doi.org/10.1016/j.jhealeco.2007.03.001

Barro, Robert J.; Sala i Martin, Xavier 1990: Economic Growth and Convergence across The United States. Working paper no. 3419. Cambridge, MA: National Bureau of Economic Research.

Bhat, P. N. Mari 2002: Completeness of India's Sample Registration System: An assessment using the general growth balance method. In: Population Studies 56,2: 119-134. https://doi.org/10.1080/00324720215930

Bhat, P. N. Mari; Navaneetham, K. 1991: Recent trends in age-specific mortality in India. In: Journal of Institute of Economic Research. J.S.S. Institute of Economic Research 26,1-2: 49-69.

Bhat, P. N. Mari; Navaneetham, K.; Rajan, S. Irudaya 1995: Maternal mortality in India: estimates from a regression model. In: Studies in family planning 26,4: 217-232. https://doi.org/10.2307/2137847

Bohk-Ewald, Christina; Ebeling, Marcus; Rau, Roland 2017: Lifespan Disparity as an Additional Indicator for Evaluating Mortality Forecasts. In: Demography 54,4: 1559-1577. https://doi.org/10.1007/s13524-017-0584-0

Bongaarts, John 2005: Long-range Trends in Adult Mortality: Models and Projection Methods. In: Demography 42,1: 23-49. https://doi.org/10.1353/dem.2005.0003

Canudas-Romo, Vladimir 2008: The modal age at death and the shifting mortality hypothesis. In: Demographic Research 19,30: 1180-1203. https://doi.org/10.4054/ DemRes.2008.19.30

Canudas-Romo, Vladimir; Saikia, Nandita; Diamond-Smith, Nadia 2016: The contribution of age-specific mortality towards male and female life expectancy differentials in India and selected States, 1970-2013. In: Asia-Pacific Population Journal 30,2: 1-20. https://doi.org/10.18356/8ec0129d-en

Carey, James Robert et al. 1992: Slowing of Mortality Rates at Older Ages in Large Medfly Cohorts. In: Science 258,5081: 457-461. https://doi.org/10.1126/science.1411540

Chaurasia, Aalok Ranjan 2010: Mortality Transition in India 1970-2005. In: Asian Population Studies 6,1: 47-68. https://doi.org/10.1080/17441731003603421

Cheung, Siu Lan Karen; Robine, Jean-Marie 2007: Increase in common longevity and the compression of mortality: The case of Japan. In: Population Studies 61,1: 85-97. https://doi.org/10.1080/00324720601103833

Cheung, Siu Lan Karen et al. 2009: Dissecting the compression of mortality in Switzerland, 1876-2005. In: Demographic Research 21,19: 569-598. https://doi.org/10.4054/ DemRes.2009.21.19

Cheung, Siu Lan Karen et al. 2005: Three Dimensions of the Survival Curve. Horizontalization, Verticalization, and Longevity Extension. In: Demography 42,2: 243-258. https://doi.org/10.1353/dem.2005.0012

Clark, Alice W. 1987: Social Demography of Excess Female Mortality in India: New Directions. In: Economic and Political Weekly 22,17: WS12-21. 
Clark, Rob 2011: World health inequality: convergence, divergence, and development. In: Social science \& medicine 72,4: 617-624. https://doi.org/10.1016/j.socscimed.2010.12.008

Coale, Ansley J. 1991: Excess Female Mortality and the Balance of the Sexes in the Population. An Estimate of the Number of "Missing Females". In: Population and Development Review 17,3: 517-523. https://doi.org/10.2307/1971953

Dowd, Kevin; Blake, David; Cairns, Andrew J. G. 2010: Facing up to uncertain life expectancy: The longevity fan charts. In: Demography 47,1: 67-78. https://doi.org/10.1353/ dem. 0.0083

Ediev, Dalkhat M. 2011: At Modal Age at Death, the Hazard Rate is Determined by its Derivative. Vienna Institute of Demography Working Papers, No. 8/2011. Vienna: Austria Academy of Sciences (OAW), Vienna Institute of Demography (VID).

Ediev, Dalkhat M. 2013: Mortality compression in period life tables hides decompression in birth cohorts in low-mortality countries. In: Genus 69,2: 53-84.

Edwards, Ryan D. 2011: Changes in World Inequality in Length of Life: 1970-2000. In: Population and Development Review 37,3: 499-528. https://doi.org/10.1111/j.1728 4457.2011.00432.x

Edwards, Ryan D.; Tuljapurkar, Shripad 2005: Inequality in Life Spans and a New Perspective on Mortality Convergence across Industrialized Countries. In: Population and Development Review 31,4: 645-674.

Engelman, Michal; Canudas-Romo, Vladimir; Agree, Emily M. 2010: The Implications of Increased Survivorship for Mortality Variation in Aging Populations. In: Population and Development Review 36,3: 511-539.

Global Burden of Disease Collaborative Network 2018: Global Burden of Disease Study 2017 (GBD 2017) Results. United States, Seattle: Institute for Health Metrics and Evaluation (IHME).

Gompertz, Benjamin 1825: On the Nature of the Function Expressive of the Law of Human Mortality, and on a New Mode of Determining the Value of Life Contingencies. In: Philosophical Transactions of the Royal Society of London 115,1825: 513-583.

Hambleton, lan R. et al. 2015: Trends in Longevity in the Americas: Disparities in Life Expectancy in Women and Men, 1965-2010. In: PLoS ONE 10,6: e0129778. https://doi. org/10.1371/journal.pone.0129778

Heligman, Larry; Pollard, John Hurlstone 1980: The age pattern of mortality. In: Journal of Institute of Actuaries 107: 49-80. https://doi.org/10.1017/S0020268100040257

Horiuchi, Shiro et al. 2013: Modal age at death: lifespan indicator in the era of longevity extension. In: Vienna Yearbook of Population Research 11,1: 37-69. https://doi. org/10.1553/populationyearbook2013s37

Horiuchi, Shiro; Wilmoth, John R. 1998: Deceleration in the Age Pattern of Mortality at Older Ages. In: Demography 35,4: 391-412.

Ibrahim, Rose Irnawaty 2008: Expanding an Abridged Life Table Using the HeligmanPollard Model. In: MATEMATIKA 24,1: 1-10.

Janssen, Fanny etnal. 2016: Sigma and beta convergence in regional mortality: A case study of the Netherlands. In: Demographic Research 35,4: 81-116. https://doi. org/10.4054/DemRes.2016.35.4

Joshi, Rohina et al. 2006: Chronic diseases now a leading cause of death in rural India mortality data from the Andhra Pradesh Rural Health Initiative. In: International journal of epidemiology 35,6: 1522-1529. https://doi.org/10.1093/ije/dyl168 
Juckett, David A.; Rosenberg, Barnett 1993: Comparison of the Gompertz and Weibull Functions as Descriptors for Human Mortality Distributions and Their Intersections. In: Mechanisms of Ageing and Development 69,1-2: 1-31. https://doi.org/10.1016/00476374(93)90068-3

Kannisto, Väinö 2000: Measuring the Compression of Mortality. In: Demographic Research 3,6. https://doi.org/10.4054/DemRes.2000.3.6

Kannisto, Väinö 2001: Mode and Dispersion of the Length of Life. In: Population: An English Selection 13,1: 159-171.

Kostaki, Anastasia; Panousis, Vangelis 2001: Expanding an abridged life table. In: Demographic Research 5,1: 1-22. https://doi.org/10.4054/DemRes.2001.5.1

Kumar, B. Gopalakrishna 1993: Low Mortality and High Morbidity in Kerala Reconsidered. In: Population and Development Review 19,1: 103-121. https://doi.org/10.2307/2938386

Lee, Ronald D. 2003: Rethinking the evolutionary theory of aging: Transfers, not births, shape senescence in social species. In: Proceedings of the National Academy of Sciences 100,16: 9637-9642. https://doi.org/10.1073/pnas.1530303100

Lynch, Scott M.; Brown, J. Scott 2001: Reconsidering Mortality Compression and Deceleration: An Alternative Model of Mortality Rates. In: Demography 38,1: 79-95. https:// doi.org/10.1353/dem.2001.0007

Makeham, William Matthew 1867: On the Law of Mortality. In: Journal of the Institute of Actuaries 13,6: 325-358.

McKee, Martin; Shkolnikov, Vladimir 2001: Understanding the toll of premature death among men in eastern Europe. In: BMJ 323,7326: 1417. https://doi.org/10.1136/ bmj.323.7326.1417a

Memoire, Aide 2007: Reproductive \& Child Health Programme Phase II, 3rd Joint Review Mission, January 15 - February 8, 2007. New Delhi, India: Ministry of Health \& Family Welfare (MoHFW).

MoHFW (Minsitry of Health and Family Welfare) 2014: Scheme for Healthcare of Women and Children. New Delhi, India: Ministry of Health \& Family Welfare (MoHFW).

Missov, Trifon l. et al. 2015: The Gompertz force of mortality in terms of the modal age at death. In: Demographic Research 32: 1031-1048. https://doi.org/10.4054/ DemRes.2015.32.36

Missov, Trifon l.; Németh, László 2015: Sensitivity of model-based human mortality measures to exclusion of the Makeham or the frailty parameter. In: Genus 71,2-3: 113135.

Moser, Kath; Shkolnikov, Vladimir; Leon, David A. 2005: World mortality 1950-2000: divergence replaces convergence from the late 1980s. In: Bulletin of the World Health Organization 83,3: 202-209.

Myers, George C.; Manton, Kenneth G. 1984: Compression of Mortality. Myth or Reality? In: The Gerentologist 24,4: 346-353. https://doi.org/10.1093/geront/24.4.346

Navaneetham, K. 1993: Mortality decline in India. an analysis of regional and temporal variations. In: Demography India 22,1: 53-63.

Németh, László 2017: Life expectancy versus lifespan inequality: A smudge or a clear relationship? In: PLoS ONE 12,9: e0185702. https://doi.org/10.1371/journal.pone.0185702

Nusselder, Wilma J.; Mackenbach, Johan P. 1996: Rectangularization of Survival Curve in the Netherlands, 1950-1992. In: The Gerontologist 36,6: 773-782. https://doi. org/10.1093/geront/36.6.773 
ORG \& CC (Office of the Registrar General \& Census Commissioner) 2015: Causes of Death Statistics 2010-13. New Delhi: Ministry of Home Affairs, Government of India.

ORG \& CC (Office of the Registrar General \& Census Commissioner) 2019: Sample Registration System. New Delhi: Ministry of Home Affairs, Government of India.

ORG (Office of the Registrar General) 1979: Medical Certification of Cause of Death 1975. New Delhi: Ministry of Home Affairs, Government of India.

ORG (Office of the Registrar General) 1986-2015: SRS Based Abridged Life Tables (197075, 1976-80, 1981-1985, 1986-1990, 1990-1994, 1991-1995, 1996-2000, 1997-2001, 2001 2005, 2003-2007, 2006-2010, 2007-2011, 2008-2012 \& 2009-2013). New Delhi: Ministry of Home Affairs, Government of India.

ORG (Office of the Registrar General) 2015: Report on Medical Cetification of Cause of Death 2013. New Delhi: Vital Statistics Division, Ministry of Home Affairs, Government of India.

ORG (Office of the Registrar General) 2019: Report on Medical Certification of Cause of Death 2017. New Delhi: Vital StatisticsDivision, Ministry of Home Affairs, Government of India.

ORG (Office of the Registrar General) 2020: SRS Bulletin. 2018. Volume 53,1. New Delhi: Vital Statistics Division, Ministry of Home Affairs, Government of India.

Paccaud, Fred et al. 1998: Age at death and rectangularisation of the survival curve. Trends in Switzerland, 1969-1994. In: Journal of Epidemiology Community Health 52,7: 412-415. https://doi.org/10.1136/jech.52.7.412

Popoff, Carole; Judson, D. H. 2004: Some Methods of Estimation for Statistically Underdeveloped Areas. In: Siegel, Jacob S.; Swanson, David A. (Eds.): The Methods and Materials of Demography. San Diego: Acadcemic Press Inc.

Rajaratnam, Julie Knoll et al. 2010: Worldwide mortality in men and women aged 15-59 years from 1970 to 2010: a systematic analysis. In: The Lancet 375,9727: 1704-1720. https://doi.org/10.1016/S0140-6736(10)60517-X

Rau, Roland et al. 2008: Continued Reductions in Mortality at Advanced Ages. In: Population and Development Reveiw 34,4: 747-768. https://doi.org/10.1111/j.1728 4457.2008.00249.x

RGI (Registrar General, India) 1972-2013: Sample Registration System Statistical Report. New Delhi: Ministry of Home Affairs, Government of India.

RGI (Registrar General, India) 2016: Compendium of India's Fertility and Mortality Indicators, 1971-2013. New Delhi: Office of the Registrar General and Census Commissioner, Ministry of Home Affairs, Government of India.

Robine, Jean-Marie 2001: Redefining the Stages of the Epidemiological Transition by a Study of the Dispersion of Life. In: Population: An English Selection 13,1: 173-194.

Saikia, Nandita et al. 2011: Trends and geographic differentials in mortality under age 60 in India. In: Population Studies 65,1: 73-89. https://doi.org/10.1080/00324728.2010 .534642

Seaman, Rosie; Leyland, Alastair H.; Popham, Frank 2016: Increasing inequality in age of death at shared levels of life expectancy: A comparative study of Scotland and England and Wales. In: SSM - population health 2: 724-731. https://doi.org/10.1016/j. ssmph.2016.10.001

Shkolnikov, Vladimir M.; Andreev, Evgeny M.; Begun, Alexander 2003: Gini coefficient as a life table function: Computation from discrete data, decomposition of differences and empirical examples. In: Demographic Research 8,11: 305-358. https://doi. org/10.4054/DemRes.2003.8.11 
Singh, Akansha; Ladusingh, Laishram 2016: Life expectancy at birth and life disparity: an assessment of sex differentials in mortality in India. In: International Journal of Population Studies 2. https://doi.org/10.18063/IJPS.2016.01.005

Smits, Jeroen; Monden, Christiaan 2009: Length of life inequality around the globe. In: Social Science \& Medicine 68,6: 1114-1123. https://doi.org/10.1016/j.socscimed.2008.12.034

Subramanian, Subu V. et al. 2006: The Mortality Divide in India: The Differential Contributions of Gender, Caste, and Standard of Living Across the Life Course. In: American Journal of Public Health 96,5: 818-825. https://doi.org/10.2105/AJPH.2004.060103

Thatcher, A. Roger et al. 2010: The compression of deaths above the mode. In: Demographic Research 22,17: 505-538. https://doi.org/10.4054/DemRes.2010.22.17

Tuljapurkar, Shripad; Li, Nan; Boe, Carl 2000: A universal pattern of mortality decline in the G7 countries. In: Nature 405,6788: 789-792. https://doi.org/10.1038/35015561

United Nations 1982: Model Life Tables for Developing Countries. New York: United Nations.

UNPD (United Nations Population Division) 2013: MORTPAK for Windows. The United Nations Software Package for Demographic Measurement. New York: Department of Economic and Social Affairs, United Nations.

Vallin, Jacques; Meslé, France 2004: Convergences and divergences in mortality. A new approach to health transition. In: Demographic Research Special Collection 2,2: 11-44. https://doi.org/10.4054/DemRes.2004.S2.2

Vaupel, James W. 1986: How change in age-specific mortality affects life expectancy. In: Population Studies 40,1: 147-157. https://doi.org/10.1080/0032472031000141896

Vaupel, James W. 2010: Biodemography of human ageing. In: Nature 464,25: 536-542. https://doi.org/10.1038/nature08984

Vaupel, James W. et al. 1998: Biodemographic Trajectories of Longevity. In: Science 280,5365: 855-860. https://doi.org/10.1126/science.280.5365.855

Vaupel, James W.; Manton, Kenneth G.; Stallard, Eric 1979: The Impact of Heterogeneity in Individual Frailty on the Dynamics of Mortality. In: Demography 16,3: 439-454 https://doi.org/10.2307/2061224

Vaupel, James W.; Zhang, Zhen; van Raalte, Alyson A. 2011: Life expectancy and disparity: an international comparison of life table data. In: BMJ open 1,1: e000128. https:// doi.org/10.1136/bmjopen-2011-000128

Visaria, Leela 2004: Mortality Trends and the Health Transition. In: Dyson, Tim; Cassen, Robert; Visaria, Leela (Eds.): Twenty-First Century India - Population, Economy, Human Development, and the Environment. New Delhi: Oxford University Press.

Wang, Haidong et al. 2016: Global, regional, national, and selected subnational levels of stillbirths, neonatal, infant, and under-5 mortality, 1980-2015: a systematic analysis for the Global Burden of Disease Study 2015. In: The Lancet 388,10053: 1725-1774. https://doi.org/10.1016/S0140-6736(16)31575-6

Wilmoth, John R.; Horiuchi, Shiro 1999: Rectangularization Revisited. Variability of Age at Death within Human Populations. In: Demography 36,4: 475-495. https://doi. org/10.2307/2648085

Yadav, Suryakant 2013: Compression or Decompression of Mortality and Morbidity in India and the Selected States. Unpublished PhD. Thesis. International Institute for Population Sciences (IIPS). Mumbai, Maharashtra, India. 
Yadav, Ajit; Ram, Faujdar 2015: Assessment of Completeness of Birth registrations (5+) by Sample Registration System (SRS) of India and Major States. In: Demography India 44,1-2: 111-118.

Yadav, Awdhesh; Yadav, Suryakant; Kesarwani, Ranjana 2012: Decelerating Mortality Rates in Older Ages and its Prospects through Lee-Carter Approach. In: PLoS ONE 7,12: e50941. https://doi.org/10.1371/journal.pone.0050941

Yadav, Suryakant; Arokiasamy, Perianayagam 2014: Understanding Epidemiological Transition in India. In: Global Health Action 7,1: 23248. https://doi.org/10.3402/gha. v7.23248

Zhang, Zhen; Vaupel, James W. 2009: The age separating early deaths from late deaths. In: Demographic Research 20,29: 721-730. https://doi.org/10.4054/DemRes.2009.20.29

Dr. Suryakant Yadav ( $₫)$, Prof. Arokiasamy Perianayagam. International Institute for Population Sciences, Department of Development Studies. Mumbai, India.

E-mail: suryakant11@gmail.com, parokiasamy@gmail.com

URL: https://www.iipsindia.ac.in/deparment-faculties/55

https://www.researchgate.net/profile/Suryakant_Yadav

https://www.researchgate.net/profile/Perianayagam_Arokiasamy 


\section{Comparative Population Studies}

WWW.comparativepopulationstudies.de

ISSN: 1869-8980 (Print) - 1869-8999 (Internet)

\section{Published by}

Prof. Dr. Norbert F. Schneider

Federal Institute for Population Research D-65180 Wiesbaden / Germany

\section{(cc) BY-SA}

2020

\section{Managing Editor}

Prof. Dr. Johannes Huinink

Dr. Katrin Schiefer

\section{Editorial Assistant}

Beatriz Feiler-Fuchs

Wiebke Hamann

\section{Layout}

Beatriz Feiler-Fuchs

E-mail:cpos@bib.bund.de

\section{Scientific Advisory Board}

Karsten Hank (Cologne)

Michaela Kreyenfeld (Berlin)

Marc Luy (Vienna)

Natalie Nitsche (Rostock)

Zsolt Spéder (Budapest)

Rainer Wehrhahn (Kiel)

\section{Board of Reviewers}

Bruno Arpino (Barcelona)

Kieron Barclay (Rostock)

Laura Bernardi (Lausanne)

Gabriele Doblhammer (Rostock)

Anette Eva Fasang (Berlin)

Michael Feldhaus (Oldenburg)

Tomas Frejka (Sanibel)

Alexia Fürnkranz-Prskawetz (Vienna)

Birgit Glorius (Chemnitz)

Fanny Janssen (Groningen)

Frank Kalter (Mannheim)

Stefanie Kley (Hamburg)

Bernhard Köppen (Koblenz)

Anne-Kristin Kuhnt (Duisburg)

Hill Kulu (St Andrews)

Nadja Milewski (Rostock)

Roland Rau (Rostock)

Thorsten Schneider (Leipzig)

Tomas Sobotka (Vienna)

Jeroen J. A. Spijker (Barcelona)

Heike Trappe (Rostock)

Helga de Valk (The Hague)

Sergi Vidal (Barcelona)

Michael Wagner (Cologne) 